\title{
Development of the Quality Assurance/Quality Control Procedures for a Neutron Interrogation System
}

\author{
Jasmina Obhođaš, Davorin Sudac, and Vladivoj Valković
}

\begin{abstract}
In order to perform Quality Assurance/Quality Control $(\mathrm{QA} / \mathrm{QC})$ procedures for a system dedicated to the neutron interrogation of objects for the presence of threat materials one needs to perform measurements of reference materials (RM) i.e. simulants having the same (or similar) atomic ratios as real materials. It is well known that explosives, drugs, and various other benign materials, contain chemical elements such as hydrogen, oxygen, carbon and nitrogen in distinctly different quantities. For example, a high carbon-to-oxygen ratio $(\mathrm{C} / \mathrm{O})$ is characteristic of drugs. Explosives can be differentiated by measurement of both $(\mathrm{C} / \mathrm{O})$ and nitrogen-to-oxygen $(\mathrm{N} / \mathrm{O})$ ratios. The $\mathrm{C} / \mathrm{N}$ ratio of the chemical warfare agents, coupled with the measurement of elements such as fluorine and phosphorus, clearly differentiate them from the conventional explosives. Here we present the RM preparation, calibration procedure and correlations attained between theoretical values and experimentally obtained results in laboratory conditions for $\mathrm{C} / \mathrm{O}$ and $\mathrm{N} / \mathrm{C}$ ratios of prepared hexogen (RDX), TNT, DLM2, TATP, cocaine, heroin, yperite, tetranitromethane, peroxide methylethylketone, nitromethane and ethyleneglycol dinitrate simulants. We have shown that analyses of the gamma ray spectra by using simple unfolding model developed for this purpose gave a nice agreement with the chemical formula of created simulants, thus the calibration quality was successfully tested.
\end{abstract}

\section{Index Terms-.}

$\mathbf{T}$ HE purpose of container inspection is to compare container cargo with its cargo manifest. Any deviation observed requires further investigation. Container inspection operations are strongly affected by the normal port operations. To this end, it is worthwhile saying that current standards and norms help in identifying suspected containers even before their arrival in the port of destination. However, the inspection of a suspected container can be done only when the container becomes available in the port area, e.g. unloaded from the ship and positioned according to the security officers' request at a specific location in the yard area. The suspected container can be inspected either manually or instrumentally. The manual container inspection is very time and resource consuming causing delays in shipping and extra costs. There is a great need to inspect shipping containers more effectively, especially after

Manuscript received June 05, 2015; revised September 18, 2015 and November 19, 2015; accepted December 07, 2015.

The authors are with the Ruđer Bošković Institute, 10000 Zagreb, Croatia (e-mail: jobhodas@irb.hr).

Color versions of one or more of the figures in this paper are available online at http://ieeexplore.ieee.org.

Digital Object Identifier 10.1109/TNS.2016.2521900

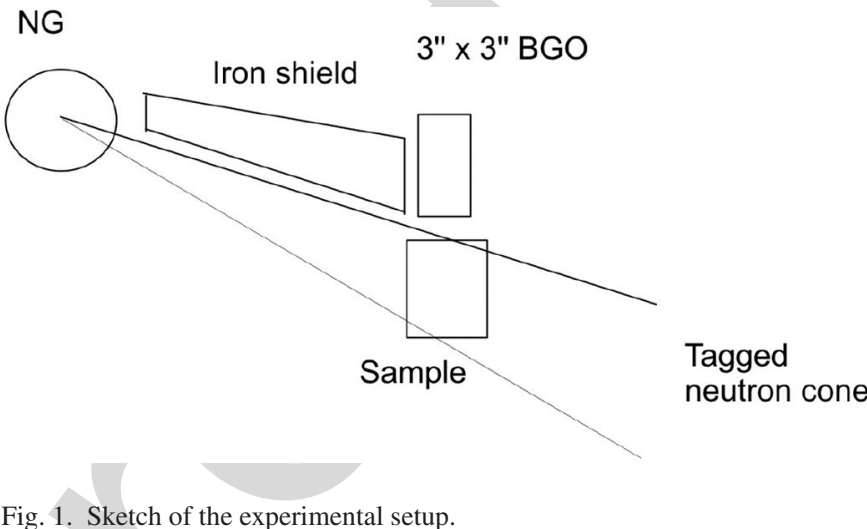

establishing US 100\% inspection regulations [1]. This triggered a lot of research towards development of advanced instrumental inspection methods [2], [3]. The fast neutron activation analysis is one of the most promising non-intrusive elemental analysis techniques for inspection of large volume cargo. It is well known that fast neutrons generated by a neutron source penetrate very deeply in the measured object and collide with the nuclei. Following the inelastic scatter with the fast neutron the nucleus emmites characteristic gamma rays which can be measured and analysed. By measuring the carbon-to-oxygen and nitrogen-to-carbon content of the measured target it is possible to identify dangerous and contraband substances [3]. Up to day the methods using fast neutrons are developed to the point that some pilot installations were built like in [3], and there are few commercial products already available at the market [4]. Yet, there are no established QA/QC procedures to control the neutron interrogation systems for preventing false positive or worse, false negative signals that would lead to underestimation of a potential danger. First steps in applying QA/QC procedures are calibration of the neutron inspection system, setting of standard reference materials and then getting the proof of compliance. In this research we were focused on detecting threat material such as bulk and liquid explosives, chemical warfare agents and drugs as a part of the QA/QC procedures. For this purpose simulants of dangerous substances with different $\mathrm{C} / \mathrm{O}$ and $\mathrm{N} / \mathrm{C}$ ratios were created. Here we present the calibration procedure done for unshielded material. Since the $\mathrm{C} / \mathrm{O}$ and N/C values depend on shielding material too, the same procedure should be repeated for different types of shielding (mineral, metal or organic matrix) which requires some a priori knowledge of the surrounding matrix. 
$\mathrm{T} 1: 1$

$\mathrm{T} 1: 2$
TABLE I

Components and Chemical Formulae of Threat Materials and Their Simulants

\begin{tabular}{|c|c|c|c|c|}
\hline Threat materials & Description & $\begin{array}{l}\text { Chemical } \\
\text { formulae }\end{array}$ & $\begin{array}{l}\text { Chemical formulae } \\
\text { of simulant }\end{array}$ & $\begin{array}{l}\text { Simulant mass } \\
\text { composition }\end{array}$ \\
\hline Hexogen (RDX) & Explosive & $\mathrm{C}_{3} \mathrm{H}_{6} \mathrm{~N}_{6} \mathrm{O}_{6}$ & $\mathrm{Si}_{3} \mathrm{C}_{3} \mathrm{H}_{6} \mathrm{~N}_{6} \mathrm{O}_{6}$ & Melamine 0.412 , Quartz sand 0.588 \\
\hline TNT & Explosive & $\mathrm{C}_{7} \mathrm{H}_{5} \mathrm{~N}_{3} \mathrm{O}_{6}$ & $\mathrm{C}_{7} \mathrm{H}_{6} \mathrm{~N}_{3} \mathrm{O}_{6}$ & $\begin{array}{l}\text { Graphite } 0.158 \text {, Oxalic acid deh. } 0.276 \text {, } \\
\text { Cyanuric acid } 0.566\end{array}$ \\
\hline TATP & Explosive & $\mathrm{C}_{9} \mathrm{H}_{18} \mathrm{O}_{6}$ & $\mathrm{C}_{9} \mathrm{H}_{16.9} \mathrm{O}_{6}$ & Sucrose 0.844 , Paraffin 0.156 \\
\hline DLM2 [7] & Mine simulant & $\mathrm{C}_{7} \mathrm{H}_{5} \mathrm{~N}_{3} \mathrm{O}_{5.5}$ & - & - \\
\hline Cocaine & Drug & $\mathrm{C}_{17} \mathrm{H}_{21} \mathrm{NO}_{4}$ & $\mathrm{C}_{17} \mathrm{H}_{21} \mathrm{NO}_{4}$ & $\begin{array}{l}\text { Melamine } 0.069 \text {, Graphite } 0.243 \text {, } \\
\text { Sucrose } 0.41 \text {, Paraffin } 0.277\end{array}$ \\
\hline Heroin & Drug & $\mathrm{C}_{21} \mathrm{H}_{23} \mathrm{NO}_{5}$ & $\mathrm{C}_{21} \mathrm{H}_{23} \mathrm{NO}_{5}$ & $\begin{array}{l}\text { Melamine } 0.057 \text {, Graphite } 0.294 \text {, } \\
\text { Sucrose } 0.421 \text {, Paraffin } 0.227\end{array}$ \\
\hline Yperite & Chemical warfare & $\mathrm{C}_{4} \mathrm{H}_{8} \mathrm{Cl}_{2} \mathrm{~S}$ & $\mathrm{C}_{4} \mathrm{H}_{8.2-8.4} \mathrm{Cl}_{2} \mathrm{SNa}_{2}$ & $\begin{array}{l}\text { Paraffin } 0.274 \text {, Sodium-chloride } 0.57 \text {, } \\
\text { Sulfur } 0.156\end{array}$ \\
\hline Tetranitromethane & Liquid explosive & $\mathrm{C}\left(\mathrm{NO}_{2}\right)_{4}$ & $\mathrm{Fe}_{4 / 9} \mathrm{C}_{4 / 3}\left(\mathrm{NO}_{2}\right)_{4} \mathrm{H}_{32 / 3}$ & $\begin{array}{l}\text { Iron(III) nitrate nonahydrate } 0.762 \text {, } \\
\text { Melamine } 0.238\end{array}$ \\
\hline Peroxide methylethylketone & Liquid explosive & $\mathrm{C}_{8} \mathrm{H}_{18} \mathrm{O}_{6}$ & $\mathrm{C}_{8} \mathrm{H}_{12} \mathrm{O}_{6}$ & Sucrose 0.914 , Graphite 0.086 \\
\hline Nitromethane & Liquid explosive & $\mathrm{CH}_{3} \mathrm{NO}_{2}$ & $\mathrm{Fe}_{1 / 3} \mathrm{CH}_{5 / 2} \mathrm{NO}_{2}$ & $\begin{array}{l}\text { Oxalic acid dehydrated } 0.398 \text {, Melamine } \\
0.266 \text {, Iron(III) oxide } 0.336\end{array}$ \\
\hline Ethyleneglycol dinitrate & Liquid explosive & $\left(\mathrm{CH}_{2} \mathrm{ONO}_{2}\right)_{2}$ & $\mathrm{FeCH}_{5 / 2} \mathrm{NO}_{3}$ & $\begin{array}{l}\text { Oxalic acid dehydrated } 0.238 \text {, Melamine } \\
0.159 \text {, Iron(III) oxide } 0.603\end{array}$ \\
\hline
\end{tabular}

TABLE II

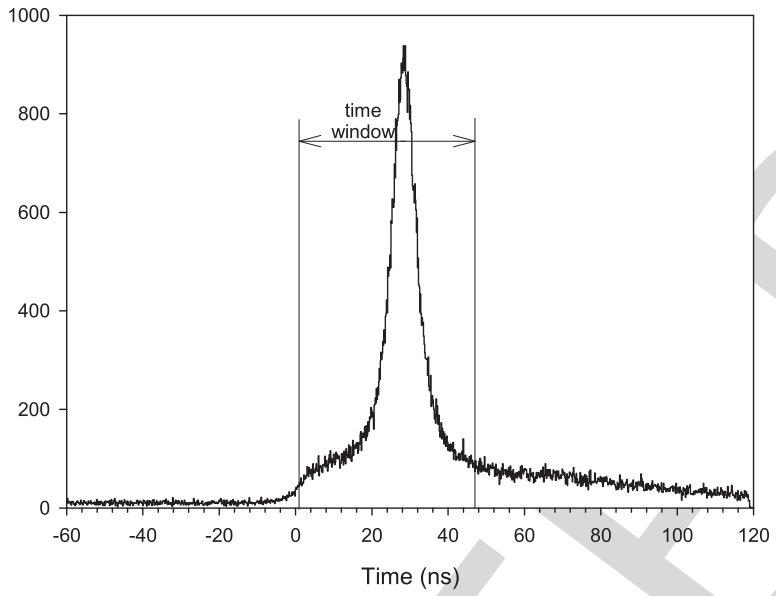

Mass COMPosition of STANDARds PREPaRed For C/O CALIBRation

$\mathrm{C} / \mathrm{O} \quad$ Composition

1/3 Graphite 0.118 , quartz sand 0.882

1/2 Graphite 0.167 , quartz sand 0.833

$1 \quad$ Graphite 0.286 , quartz sand 0.714

$2 \quad$ Graphite 0.444 , quartz sand 0.556

$4 \quad$ Graphite 0.615 , quartz sand 0.385

TABLE III

MASS COMPosition of Standards Prepared For N/C CALIBRATION T3:2

\begin{tabular}{ll}
$\mathrm{N} / \mathrm{C}$ & Composition \\
\hline $1 / 21$ & Iron(III) nitrate nonahydrate 0.348, graphite 0.652 \\
$3 / 7$ & Iron(III) nitrate nonahydrate 0.828, graphite 0.172 \\
2.5 & Iron(III) nitrate nonahydrate 0.616, melamine 0.384 \\
3.5 & Iron(III) nitrate nonahydrate 0.828, melamine 0.172
\end{tabular}

F2:1 Fig. 2. Typical time-of-flight spectrum (output from TAC) with indicated time $\mathrm{F} 2: 2$ window used in data analysis.

\section{METHODS}

Fig. 1 shows the experimental setup. A neutron generator (NG) ThermoElectron API 120 was used as a source of $14 \mathrm{MeV}$ (fast) neutrons (cca $10^{7} \mathrm{n} / \mathrm{s}$ in $4 \pi$ ) produced by ${ }^{3} \mathrm{H}(\mathrm{d}, \mathrm{n}){ }^{4} \mathrm{He}$ nuclear reaction. Since ${ }^{4} \mathrm{He}$ (alpha) particle is produced in opposite direction from the neutron, it is possible to tag and electronically collimate neutrons by detecting coincides between alpha particles and gamma rays emitted from the nuclei in the measured object excited by the inelastic scattering with tagged neutrons [6]. The alpha detector incorporated inside the NG was made from the YAP:Ce scintillator fixed to the NG, and removable photomultiplier tube (PMT). The collimator in front of the PMT defined the tagged neutron cone opening angle of $12^{\circ}$. The $7.62 \mathrm{~cm} \times 7.62 \mathrm{~cm}$ Bismuth Germanium Oxide, $\mathrm{Bi}_{4} \mathrm{Ge}_{3} \mathrm{O}_{12}$ detector (BGO) was used for the detection of characteristic gamma rays. The BGO energy resolution was $7 \%$ at $4.44 \mathrm{MeV}$ carbon peak. A pyramid made of iron, $40 \mathrm{~cm}$ in length, was used as a shield for detector protection from direct neutron radiation. A measured sample was put below the gamma ray detector $5 \mathrm{~cm}$ apart from the detector. The distance between the neutron source and the gamma

F3:1 Fig. 3. Gamma spectra of elements used for fitting procedure. 
$\mathrm{T} 4: 1$

T4:2

T5:1

T5:2

T6:1

T6:2

T7:1

T7:2

T8:1

T8:2

TABLE IV

UNFOLDING RESULTS FOR C/O CALIBRATION STANDARDS

\begin{tabular}{lllllll}
$\mathrm{C} / \mathrm{O}$ & Oxygen $(\mathrm{a})$ & Carbon $(\mathrm{b})$ & Nitrogen $(\mathrm{c})$ & Iron $(\mathrm{d})$ & Silicon $(\mathrm{e})$ & $\mathrm{b} / \mathrm{a}$ \\
\hline $1 / 3$ & $0.45 \pm 0.007$ & $0.135 \pm 0.005$ & $-0.03 \pm 0.01$ & $-0.10 \pm 0.01$ & $0.54 \pm 0.01$ & $0.30 \pm 0.01$ \\
$1 / 2$ & $0.395 \pm 0.008$ & $0.160 \pm 0.005$ & $-0.01 \pm 0.01$ & $-0.015 \pm 0.012$ & $0.47 \pm 0.01$ & $0.405 \pm 0.015$ \\
1 & $0.326 \pm 0.009$ & $0.277 \pm 0.006$ & $-0.008 \pm 0.01$ & $0.032 \pm 0.014$ & $0.37 \pm 0.01$ & $0.85 \pm 0.03$ \\
2 & $0.259 \pm 0.008$ & $0.401 \pm 0.006$ & $0.03 \pm 0.01$ & $-0.01 \pm 0.01$ & $0.31 \pm 0.01$ & $1.55 \pm 0.05$ \\
4 & $0.181 \pm 0.009$ & $0.588 \pm 0.007$ & $0.005 \pm 0.01$ & $0.02 \pm 0.01$ & $0.20 \pm 0.01$ & $3.25 \pm 0.2$ \\
\hline
\end{tabular}

TABLE V

actual Relative Mass Concentration of Oxygen, Carbon, Nitrogen, Iron and Silicon for C/O Calibration Standards

\begin{tabular}{lcccccc} 
C/O & Oxygen & Carbon & Nitrogen & Iron & Silicon & Carbon/Oxygen \\
\hline $1 / 3$ & 0.47 & 0.12 & 0 & 0 & 0.41 & 0.25 \\
$1 / 2$ & 0.44 & 0.17 & 0 & 0 & 0.39 & 0.39 \\
1 & 0.38 & 0.29 & 0 & 0 & 0.33 & 0.76 \\
2 & 0.30 & 0.44 & 0 & 0 & 0.18 & 1.47 \\
4 & 0.21 & 0.61 & 0 & 0 & 0.18 & 2.90 \\
\hline
\end{tabular}

TABLE VI

UNFOLDING RESULTS FOR N/C CALIBRATION STANDARDS

\begin{tabular}{lclllll}
$\mathrm{N} / \mathrm{C}$ & Oxygen $(\mathrm{a})$ & Carbon $(\mathrm{b})$ & Nitrogen $(\mathrm{c})$ & Iron $(\mathrm{d})$ & Silicon $(\mathrm{e})$ & $\mathrm{c} / \mathrm{b}$ \\
\hline $1 / 21$ & $0.245 \pm 0.009$ & $0.622 \pm 0.008$ & $0.06 \pm 0.01$ & $0.12 \pm 0.01$ & $-0.055 \pm 0.01$ & $0.096 \pm 0.023$ \\
$3 / 7$ & $0.676 \pm 0.009$ & $0.172 \pm 0.006$ & $0.10 \pm 0.01$ & $0.075 \pm 0.01$ & $0.0131 \pm 0.0095$ & $0.59 \pm 0.08$ \\
2.5 & $0.480 \pm 0.010$ & $0.133 \pm 0.006$ & $0.285 \pm 0.015$ & $0.11 \pm 0.01$ & $0.025 \pm 0.01$ & $2.14 \pm 0.15$ \\
3.5 & $0.585 \pm 0.010$ & $0.068 \pm 0.007$ & $0.19 \pm 0.02$ & $0.15 \pm 0.02$ & $0.02 \pm 0.01$ & $3.0 \pm 0.5$ \\
\hline
\end{tabular}

TABLE VII

Actual Relative Mass Concentration of Oxygen, CARbon, Nitrogen, Iron and Silicon for N/C Calibration Standards

\begin{tabular}{lclclcc} 
N/C & Oxygen & Carbon & Nitrogen & Iron & Silicon & Nitrogen/Carbon \\
\hline $1 / 21$ & 0.248 & 0.652 & 0.036 & 0.048 & 0 & 0.055 \\
$3 / 7$ & 0.590 & 0.172 & 0.086 & 0.114 & 0 & 0.5 \\
2.5 & 0.439 & 0.11 & 0.320 & 0.085 & 0 & 2.9 \\
3.5 & 0.590 & 0.049 & 0.201 & 0.114 & 0 & 4.1 \\
\hline
\end{tabular}

TABLE VIII

Unfolding Results For MEASUREd Simulants of Threat Materials

\begin{tabular}{llllll} 
Item (simulants) & Oxygen (a) & Carbon (b) & Nitrogen (c) & Iron (d) & Silicon (e) \\
\hline Hexogen (RDX) & $0.297 \pm 0.009$ & $0.126 \pm 0.006$ & $0.220 \pm 0.01$ & $0.011 \pm 0.014$ & $0.35 \pm 0.01$ \\
TNT & $0.45 \pm 0.01$ & $0.369 \pm 0.007$ & $0.20 \pm 0.01$ & $0.007 \pm 0.01$ & $-0.002 \pm 0.01$ \\
TATP & $0.45 \pm 0.01$ & $0.535 \pm 0.008$ & $0.02 \pm 0.01$ & $0.02 \pm 0.01$ & $-0.04 \pm 0.01$ \\
DLM2 & $0.34 \pm 0.01$ & $0.35 \pm 0.008$ & $0.15 \pm 0.02$ & $0.165 \pm 0.017$ & $0.01 \pm 0.01$ \\
Cocaine & $0.205 \pm 0.009$ & $0.748 \pm 0.008$ & $0.082 \pm 0.014$ & $0.038 \pm 0.015$ & $-0.05 \pm 0.01$ \\
Heroin & $0.24 \pm 0.009$ & $0.762 \pm 0.008$ & $0.03 \pm 0.014$ & $0.033 \pm 0.014$ & $-0.04 \pm 0.01$ \\
Yperite & - & - & - & - & $-0.015 \pm 0.012$ \\
Tetranitromethane & $0.53 \pm 0.01$ & $0.087 \pm 0.007$ & $0.222 \pm 0.015$ & $0.163 \pm 0.015$ & 0.015 \\
Peroxide methylethylketone & $0.488 \pm 0.009$ & $0.525 \pm 0.007$ & $0.007 \pm 0.013$ & $0.017 \pm 0.013$ & $-0.02 \pm 0.01$ \\
Nitromethane & $0.447 \pm 0.009$ & $0.16 \pm 0.006$ & $0.19 \pm 0.01$ & $0.21 \pm 0.01$ & $0.01 \pm 0.01$ \\
Ethyleneglycol dinitrate & $0.408 \pm 0.009$ & $0.111 \pm 0.006$ & $0.12 \pm 0.01$ & $0.37 \pm 0.01$ & $0.015 \pm 0.01$ \\
\hline
\end{tabular}

ray detector was $50 \mathrm{~cm}$. All samples had mass of $1 \mathrm{~kg}$, except DLM2 anti-personal mine simulant [7] which mass was $192.6 \mathrm{~g}$ and volume $\Phi 80 \mathrm{~mm} \times 34.5 \mathrm{~mm}$.

Measured samples, chemical formulae of the real materials and measured simulants (when applicable), as well as compounds used to make simulants are presented in Table I.

Each measurement lasted $1000 \mathrm{~s}$ and was normalized to the same number of emitted tagged neutrons. The fast output from the alpha detector was fed through the constant fraction discriminator (CFD) and delay line to the STOP of the timeto-amplitude converter (TAC). The fast output from the gamma ray detector was fed through the timing filter amplifier and CFD to the START of the TAC. A slow signal from the gamma ray 110 detector was fed through the amplifier to the analog-to-digital 111 converter (ADC) incorporated inside the personal computer 112 together with the output from TAC (time spectrum). The ADC 113 was triggered by a single channel analyzer (SCA) output from 114 TAC. Fig. 2 shows the typical time spectrum. A wider time win- 115 dow was used for the gamma ray spectra analysis in order to 116 obtain more statistics (counts) and accordingly smaller error 117 bars in the gamma ray peaks. This improved the detection 118 probabilities.

Gamma ray spectra were fitted according to the equation (1) 120 which is simple unfolding model developed for this purpose. 121 
T9:1

TABLE IX

Actual Relative Mass Concentration of Oxygen, Carbon, Nitrogen, Iron and Silicon for Simulants of Threat Materials

\begin{tabular}{llllll} 
Item (simulants) & Oxygen & Carbon & Nitrogen & Iron & Silicon \\
\hline Hexogen (RDX) & 0.313 & 0.118 & 0.274 & 0 & 0.275 \\
TNT & 0.421 & 0.368 & 0.184 & 0 & 0 \\
TATP & 0.434 & 0.489 & 0 & 0 & 0 \\
DLM2 & 0.401 & 0.384 & 0.192 & 0 & 0 \\
Cocaine & 0.211 & 0.673 & 0.046 & 0 & 0 \\
Heroin & 0.216 & 0.683 & 0.038 & 0 & 0 \\
Yperite & - & - & - & - & - \\
Tetranitromethane & 0.543 & 0.068 & 0.238 & 0.105 & 0 \\
Peroxide methylethylketone & 0.470 & 0.471 & 0 & 0 & 0 \\
Nitromethane & 0.404 & 0.152 & 0.177 & 0.235 & 0 \\
Ethyleneglycol dinitrate & 0.362 & 0.091 & 0.106 & 0.422 & 0 \\
\hline
\end{tabular}

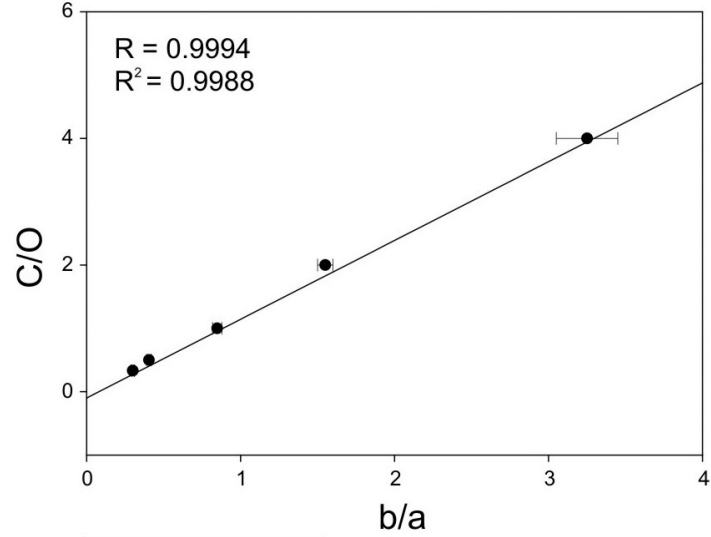

- fitting curve experimental data

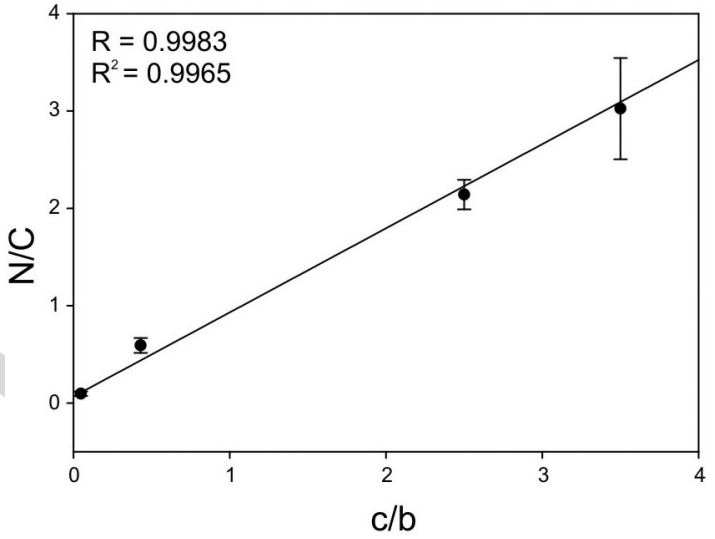

experimental data
F4:1 Fig. 4. The stoichiometric $\mathrm{C} / \mathrm{O}$ values in dependence on the fitting parameters $\mathrm{F} 4: 2$ ratio for $\mathrm{C} / \mathrm{O}$ calibration standards. Standard error of estimate: $6 \%$.
Fig. 5. The stoichiometric N/C values in dependence on the fitting parameters F5:1 ratio for N/C calibration standards. Standard error of estimate: $12 \%$.

$$
\begin{aligned}
& \chi^{2}=\frac{\text { summ }^{2}}{c h_{\max }-c h_{\min }-5+1} \\
& \times \sum_{c h=c h_{\min }}^{c h_{\max }} \frac{\left(a \times O(c h)+b \times C(c h)+c \times N(c h)+d \times F e(c h)+e \times S i(c h)-\frac{T \arg \text { et }(\text { ch })}{\text { summ }}\right)^{2}}{T \arg e t(c h)} \\
& \sum_{c h=c h_{\min }}^{c h_{\max }} T \arg \operatorname{et}(\mathrm{ch})=\operatorname{summ} \\
& \sum_{c h=c h_{\min }}^{c h_{\max }} O(c h)=1 \\
& \sum_{c h=c h_{\min }}^{c h_{\max }} C(c h)=1 \\
& \sum_{c h=c h_{\min }}^{c h_{\max }} N(c h)=1 \\
& \sum_{c h=c h_{\min }}^{c h_{\max }} F e(c h)=1 \\
& \sum_{c h=c h_{\min }}^{c h_{\max }} S i(c h)=1
\end{aligned}
$$



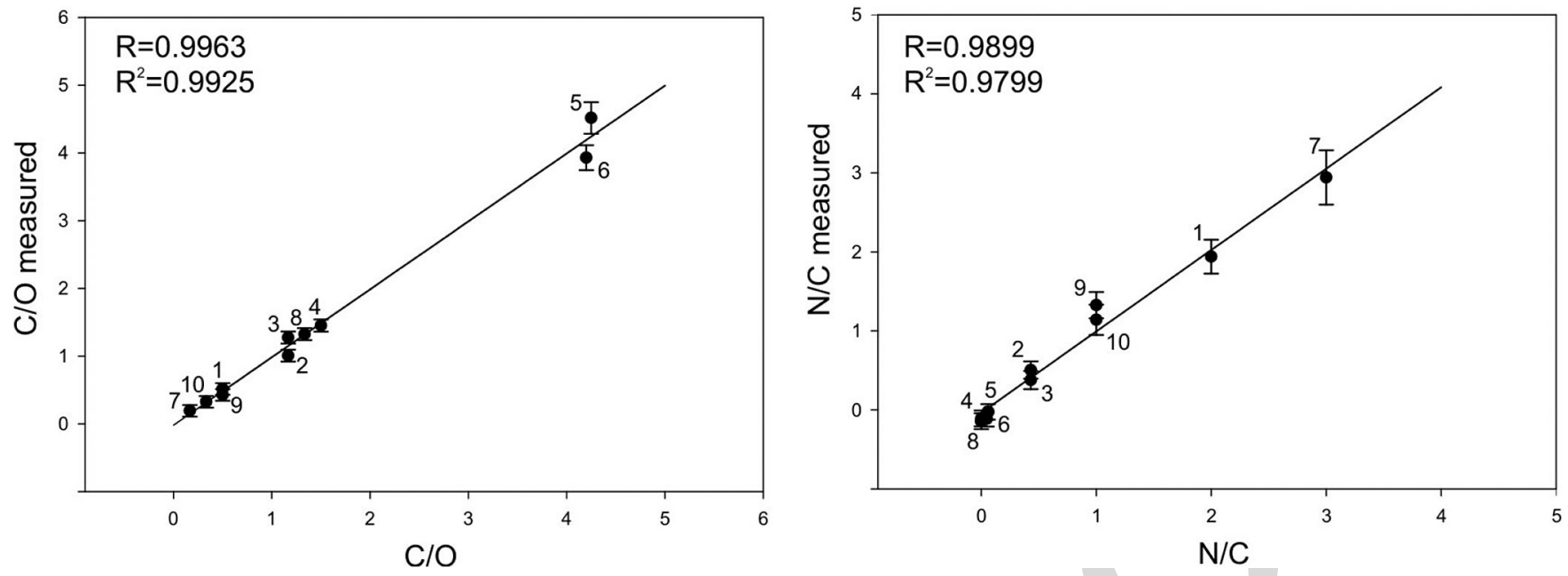

F6:1 Fig. 6. Correlations between stoichiometric and experimentally obtained values for C/O ratio (left) and N/C ratio (right) for different types of threat materials as F6:2 shown in Tables X and XI.

T10:1
TABLE X

Comparison Between Measured and Stoichiometric C/O Values OF THREAT MATERIAL Simulants

\begin{tabular}{|c|c|c|c|c|}
\hline ID & Simulant & $\begin{array}{l}\mathrm{C} / \mathrm{O} \text { from } \\
\text { stoichiometry }\end{array}$ & $\begin{array}{l}\mathrm{C} / \mathrm{O} \text { from } \\
\text { measurement }\end{array}$ & Difference \\
\hline 1. & Hexogen & 0.500 & $0.514 \pm 0.085$ & $-0.16 \sigma$ \\
\hline 2. & TNT & 1.17 & $1.01 \pm 0.09$ & $1.8 \sigma$ \\
\hline 3. & DLM2 & 1.17 & $1.27 \pm 0.09$ & $-1.1 \sigma$ \\
\hline 4. & TATP & 1.50 & $1.45 \pm 0.09$ & $0.55 \sigma$ \\
\hline 5. & Cocaine & 4.25 & $4.52 \pm 0.23$ & $-1.2 \sigma$ \\
\hline 6. & Heroin & 4.2 & $3.9 \pm 0.2$ & $1.5 \sigma$ \\
\hline 7. & $\begin{array}{l}\text { Tetranitro- } \\
\text { methane }\end{array}$ & 0.167 & $0.192 \pm 0.085$ & $0.3 \sigma$ \\
\hline 8. & $\begin{array}{l}\text { Peroxide } \\
\text { methyl- } \\
\text { ethylketone }\end{array}$ & 1.33 & $1.32 \pm 0.09$ & $0.11 \sigma$ \\
\hline 9. & Nitromethane & 0.500 & $0.428 \pm 0.085$ & $0.85 \sigma$ \\
\hline 10. & $\begin{array}{c}\text { Ethylenglycol } \\
\text { dinitrate }\end{array}$ & 0.333 & $0.324 \pm 0.085$ & $0.1 \sigma$ \\
\hline ID & Simulant & $\begin{array}{l}\text { N/C from } \\
\text { stoichiometry }\end{array}$ & $\begin{array}{l}\mathrm{N} / \mathrm{C} \text { from } \\
\text { measurement }\end{array}$ & Difference \\
\hline 1. & Hexogen & 2 & $1.9 \pm 0.2$ & $0.5 \sigma$ \\
\hline 2. & TNT & 0.43 & $0.5 \pm 0.1$ & $-0.7 \sigma$ \\
\hline 3. & DLM2 & 0.43 & $0.4 \pm 0.1$ & $0.3 \sigma$ \\
\hline 4. & TATP & 0 & $-0.1 \pm 0.1$ & $1 \sigma$ \\
\hline 5. & Cocaine & 0.059 & $-0.026 \pm 0.098$ & $0.9 \sigma$ \\
\hline 6. & Heroin & 0.0476 & $-0.112 \pm 0.098$ & $1.6 \sigma$ \\
\hline 7. & $\begin{array}{l}\text { Tetranitro- } \\
\text { methane }\end{array}$ & 3 & $2.9 \pm 0.3$ & $0.3 \sigma$ \\
\hline 8. & $\begin{array}{l}\text { Peroxide } \\
\text { methyl- } \\
\text { ethylketone }\end{array}$ & 0 & $-0.1 \pm 0.1$ & $1 \sigma$ \\
\hline 9. & Nitromethane & 1 & $1.3 \pm 0.2$ & $1.5 \sigma$ \\
\hline 10. & $\begin{array}{c}\text { Ethylenglycol } \\
\text { dinitrate }\end{array}$ & 1 & $1.1 \pm 0.2$ & $0.5 \sigma$ \\
\hline
\end{tabular}

The model assumes that gamma ray spectra contain only the following chemical elements: oxygen, carbon, nitrogen, iron and silicon. The fitting parameters from eq. (1) are marked with "a" for oxygen, "b" for carbon, "c" for nitrogen, "d" for iron and "e" for silicon and the values are summed from minimum to maximum channel and normalized to 1 . The method of least squares states that the best value of "a", "b", "c", "d" and "e"

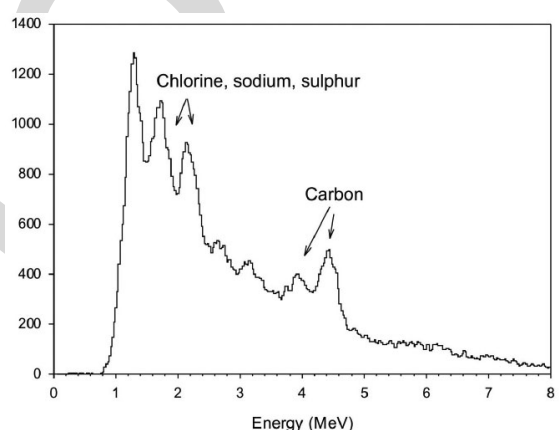

Fig. 7. Gamma spectrum obtained for yperite simulant.

are the one for which the reduced chi-square (defined in eq.1 130 and [8]) is minimal. In practice, values of reduced chi-square 131 close to 1 are acceptable for obtaining a good spectrum fitting. 132 [See equation (1), shown at the bottom of the previous page.] 133

A number of counts in the gamma ray spectra of carbon are 134 marked with C (ch) and similarly for other elements. A num- 135 ber of counts in the sample spectrum are marked with Target 136 (ch). Spectra obtained for elements oxygen, carbon, nitrogen, 137 iron and silicon are presented in Fig. 3. Oxygen spectrum was 138 obtained by analysis of water, carbon spectrum by analysis of 139 graphite, iron spectrum by analysis of the iron metal plate, 140 nitrogen spectrum by analysis of melamine from which the 141 carbon contribution was subtracted and silicon spectrum was 142 obtained by analysis of quartz sand. In order to quantitatively 143 determine $\mathrm{C} / \mathrm{O}$ and $\mathrm{N} / \mathrm{C}$ ratios, standard materials of known 144 $\mathrm{C} / \mathrm{O}$ and N/C ratios were prepared for calibration purposes 145 as shown in Tables II and III. The C/O and N/C ratios were 146 selected because the differences in their values distinguish the 147 wide spectrum of threat materials.

\section{RESUlTS AND DISCUSSION}

Aim of the developed calibration procedure was to relate the 150 measured $\mathrm{b} / \mathrm{a}$ and $\mathrm{c} / \mathrm{b}$ ratios with the stoichiometric values of the 151 calibration standards which compositions are shown in Table II 152 

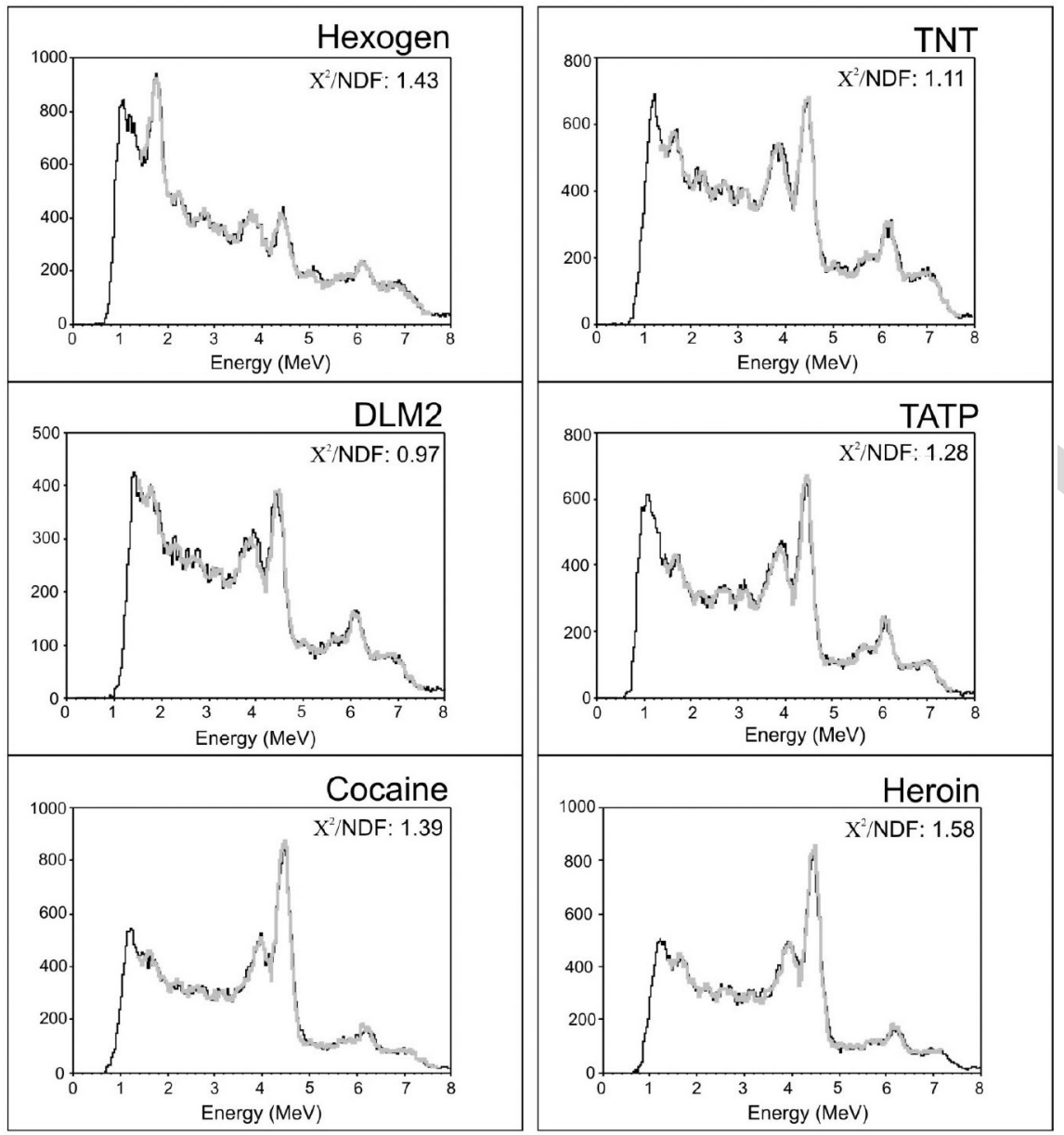

F8:1 Fig. 8. Gamma spectra for simulants of bulk explosives, cocaine and heroin. Fitted spectra are in grey.
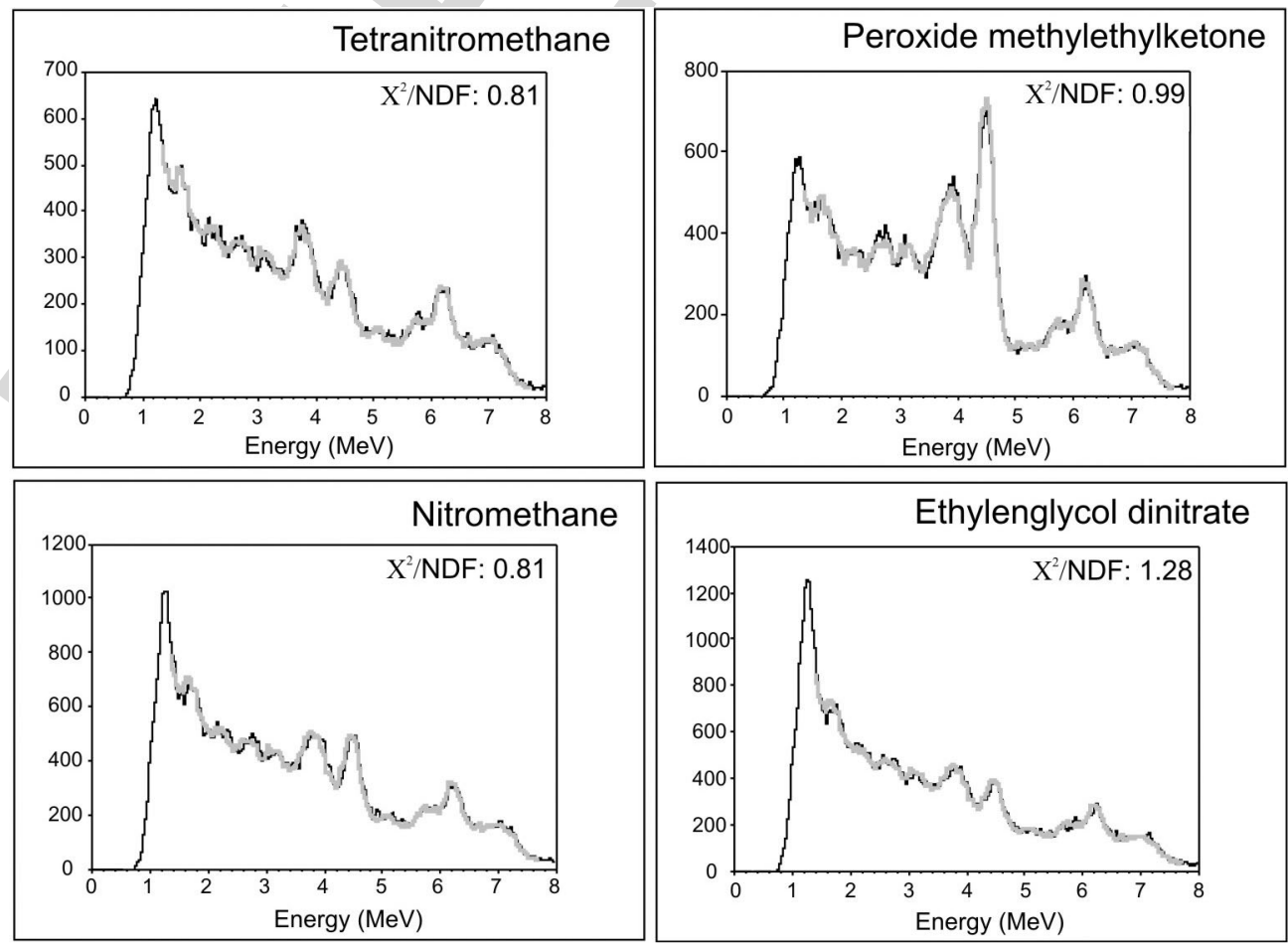

F9:1 Fig. 9. Gamma spectra for simulants of liquid explosives. Fitted spectra are in grey. 
and III. The method of least squares was used to obtain "a", "b", "c", "d" and "e" fitting parameters with minimum chi-square value which results are presented in Table IV and VI. Negative values of fitting parameters have to be interpreted as zero values within the standard errors of estimate. Actual relative mass concentration of oxygen, carbon, nitrogen, iron and silicon for $\mathrm{C} / \mathrm{O}$ and $\mathrm{N} / \mathrm{C}$ calibration standards are given in table $\mathrm{V}$ and VII, respectively. Figs. 4 and 5 show the stoichiometric $\mathrm{C} / \mathrm{O}$ and $\mathrm{N} / \mathrm{C}$ values in dependence on the fitting parameter ratios b/a and $\mathrm{c} / \mathrm{b}$, respectively. Lines were fitted through the experimentally obtained points with the fitting parameters shown in eq. (2) and (3). These calibration lines were used to obtain experimental $\mathrm{C} / \mathrm{O}$ and N/C values for measured simulants. Fitting parameters obtained for "a", "b", "c", "d" and "e" in simulants are presented in Table VIII and actual relative mass concentrations of $\mathrm{O}, \mathrm{Si}, \mathrm{N}, \mathrm{Fe}$ and $\mathrm{Si}$ in simulants in Table IX.

Linear correlations between theoretical and experimental ratios of $\mathrm{C} / \mathrm{O}$ and N/C for hexogen (RDX), TNT, DLM2, TATP, cocaine, heroin, tetranitromethane, peroxide methylethylketone, nitromethane and ethylenglycol dinitrate are shown in eq. (4) and (5) and Fig. 6. Expected slope and segment of the correlation function are 1 and 0 , respectively. The total error comprises errors obtained for segment and slope. Since both $\mathrm{C} / \mathrm{O}$ and N/C ratios have slopes and segments close to 1 and 0 respectively (within the error bar), it can be concluded that the calibration procedure is consistent. Tables $\mathrm{X}$ and $\mathrm{XI}$ show the comparison between measured and stoichiometric $\mathrm{C} / \mathrm{O}$ and $\mathrm{N} / \mathrm{C}$ values respectively, as well as the individual errors resulting from the spectrum fitting. The error bars depend on many factors, however they diminish with the extension of the measurement time. This calibration procedure enables experimental determination of $\mathrm{C} / \mathrm{O}$ and $\mathrm{N} / \mathrm{C}$ values by analyzing the adequate standards (Tables II and III) and testing the quality of calibration by analyzing simulants prepared as reference materials (Table I). This approach is different compared to the methodology described in [5] where Monte Carlo simulation was used to determine $\mathrm{C} / \mathrm{O}$ and $\mathrm{N} / \mathrm{C}$ values. Applied calibration procedure should be repeated for a shielded material, e.g. for inspected material shielded within metal, mineral or organic matrix having realistic densities obtained from a real cargo [9]. By using this procedure it is possible to obtain correction factors for different types of cargo.

$\mathrm{C} / \mathrm{O}($ experimental $)=(-0.1 \pm 0.04)+(1.244 \pm 0.025) \mathrm{b} / \mathrm{a}$

$\mathrm{N} / \mathrm{C}($ experimental $)=(-0.16 \pm 0.095)+(1.215 \pm 0.051) \mathrm{c} / \mathrm{b}$

$\mathrm{C} / \mathrm{O}=(-0.02 \pm 0.07)+(1.0 \pm 0.03) \mathrm{C} / \mathrm{O}($ experimental $)$

$\mathrm{N} / \mathrm{C}=(-0.04 \pm 0.07)+(1.03 \pm 0.05) \mathrm{N} / \mathrm{C}($ experimental $)$
Fig. 7 presents gamma spectrum obtained for yperite. This 195 spectrum was not fitted since it does not contain $\mathrm{N}$ and O peaks. 196 Fig. 8 presents fitted gamma spectra of measured bulk explo- 197 sives and drugs and Fig. 9 shows fitted spectra of measured 198 liquid explosives. Note that the reduced chi-squares of fitted 199 spectra showed in Fig. 8 and 9 were all close to one, hence the 200 fitting results are acceptable.

\section{CONCLUSION}

We have proposed new experimental approach for the neu- 203 tron interrogation system calibration. Calibration standards and 204 simulants of threat materials were created. Materials and quan- 205 tities necessary for their production have been listed, thus 206 developers of neutron interrogation systems can produce their 207 own calibration standards and threat material simulants as ref- 208 erence materials. A simple unfolding model for determination 209 of $\mathrm{C} / \mathrm{O}$ and N/C ratios has been developed. It has been shown 210 that analyses of the gamma ray spectra by using this unfolding 211 model gave a nice agreement with the C/O and N/C stoichio- 212 metric ratios of simulants, hence the calibration quality was 213 successfully tested. In future work influence of the surround- 214 ing matrix to $\mathrm{C} / \mathrm{O}$ and $\mathrm{N} / \mathrm{C}$ ratios in simulants of threat material 215 will be studied.

\section{ACKNOWLEDGMENT}

The authors would like to express their gratitude to unknown 218 reviewers whose careful reading and comments significantly 219 improved the paper.

\section{REFERENCES}

[1] Secure Freight Initiative, Section 232 of the Safe Ports Act of 2006. 222

[2] V. Valkovic et al., "Inspection of shipping containers for threat materials," 223 Radiat. Phys. Chem., vol. 71, pp. 897-898, 2004.

[3] C. Carasco et al., "In-field tests of the EURITRACK tagged neutron 225 inspection system," Nucl. Instrum. Methods Phys. Res. A, vol. 588, 226 pp. 397-405, 2008 .

[4] Examples: http://neutrontech.jinr.ru/index.php?id=products, http://www. 228 sodern.com/sites/en/ref/Homeland-Security-and-Defense_34.html 229

[5] W. El Kanawati et al., "Conversion factors from counts to chemical ratios 230 for the EURITRACK tagged neutron inspection system," Nucl. Instrum. 231 Methods Phys. Res. A, vol. 654, pp. 621-629, 2011.

[6] D. Sudac, S. Blagus, V. Valkovic, "Inspections for contraband in a 233 shipping container using fast neutrons and the associated alpha parti- 234 cle technique: Proof of principle," Nucl. Instrum. Methods Phys. Res. B, 235 vol. 241, pp. 798-803, 2005.

[7] F. D. Brooks, M. Drosg, A. Buffler, and M. S. Allie, "Detection of antipersonnel landmines by neutron scattering and attenuation," Appl. Radiat. 238 Isot., vol. 61, pp. 27-34, 2004.

[8] W. R. Leo, Techniques for Nuclear and Particle Physics Experiments, 240 Berlin, Germany: Springer-Verlag, 1987, pp. 99.

[9] J. Obhodas et al., "Analysis of containerized cargo in the ship container 242 terminal," Nucl. Instrum. Methods Phys. Res. A, vol. 619, pp. 460-466, 243 2010 . 


\section{QUERY}

Q1: Please supply index terms/keywords for your paper. To download the IEEE Taxonomy, go to http://www.ieee.org/documents/ taxonomy_v101.pdf. 


\title{
Development of the Quality Assurance/Quality Control Procedures for a Neutron Interrogation System
}

\author{
Jasmina Obhođaš, Davorin Sudac, and Vladivoj Valković
}

\begin{abstract}
In order to perform Quality Assurance/Quality Control $(\mathrm{QA} / \mathrm{QC})$ procedures for a system dedicated to the neutron interrogation of objects for the presence of threat materials one needs to perform measurements of reference materials (RM) i.e. simulants having the same (or similar) atomic ratios as real materials. It is well known that explosives, drugs, and various other benign materials, contain chemical elements such as hydrogen, oxygen, carbon and nitrogen in distinctly different quantities. For example, a high carbon-to-oxygen ratio $(\mathrm{C} / \mathrm{O})$ is characteristic of drugs. Explosives can be differentiated by measurement of both $(\mathrm{C} / \mathrm{O})$ and nitrogen-to-oxygen $(\mathrm{N} / \mathrm{O})$ ratios. The $\mathrm{C} / \mathrm{N}$ ratio of the chemical warfare agents, coupled with the measurement of elements such as fluorine and phosphorus, clearly differentiate them from the conventional explosives. Here we present the RM preparation, calibration procedure and correlations attained between theoretical values and experimentally obtained results in laboratory conditions for $\mathrm{C} / \mathrm{O}$ and $\mathrm{N} / \mathrm{C}$ ratios of prepared hexogen (RDX), TNT, DLM2, TATP, cocaine, heroin, yperite, tetranitromethane, peroxide methylethylketone, nitromethane and ethyleneglycol dinitrate simulants. We have shown that analyses of the gamma ray spectra by using simple unfolding model developed for this purpose gave a nice agreement with the chemical formula of created simulants, thus the calibration quality was successfully tested.
\end{abstract}

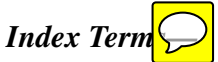

$\mathbf{T}$ HE purpose of container inspection is to compare container cargo with its cargo manifest. Any deviation observed requires further investigation. Container inspection operations are strongly affected by the normal port operations. To this end, it is worthwhile saying that current standards and norms help in identifying suspected containers even before their arrival in the port of destination. However, the inspection of a suspected container can be done only when the container becomes available in the port area, e.g. unloaded from the ship and positioned according to the security officers' request at a specific location in the yard area. The suspected container can be inspected either manually or instrumentally. The manual container inspection is very time and resource consuming causing delays in shipping and extra costs. There is a great need to inspect shipping containers more effectively, especially after

Manuscript received June 05, 2015; revised September 18, 2015 and November 19, 2015; accepted December 07, 2015.

The authors are with the Ruđer Bošković Institute, 10000 Zagreb, Croatia (e-mail: jobhodas@irb.hr).

Color versions of one or more of the figures in this paper are available online at http://ieeexplore.ieee.org.

Digital Object Identifier 10.1109/TNS.2016.2521900

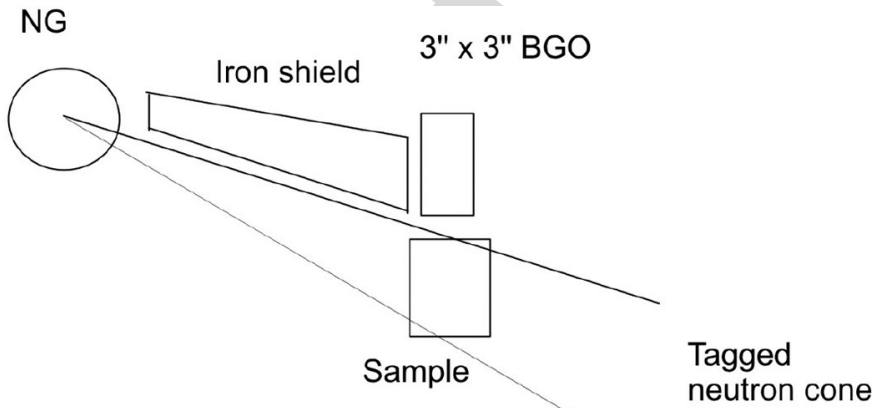

Fig. 1. Sketch of the experimental setup.

establishing US 100\% inspection regulations [1]. This triggered a lot of research towards development of advanced instrumental inspection methods [2], [3]. The fast neutron activation analysis is one of the most promising non-intrusive elemental analysis techniques for inspection of large volume cargo. It is well known that fast neutrons generated by a neutron source penetrate very deeply in the measured object and collide with the nuclei. Following the inelastic scatter with the fast neutron the nucleus emmites characteristic gamma rays which can be measured and analysed. By measuring the carbon-to-oxygen and nitrogen-to-carbon content of the measured target it is possible to identify dangerous and contraband substances [3]. Up to day the methods using fast neutrons are developed to the point that some pilot installations were built like in [3], and there are few commercial products already available at the market [4]. Yet, there are no established QA/QC procedures to control the neutron interrogation systems for preventing false positive or worse, false negative signals that would lead to underestimation of a potential danger. First steps in applying QA/QC procedures are calibration of the neutron inspection system, setting of standard reference materials and then getting the proof of compliance. In this research we were focused on detecting threat material such as bulk and liquid explosives, chemical warfare agents and drugs as a part of the QA/QC procedures. For this purpose simulants of dangerous substances with different $\mathrm{C} / \mathrm{O}$ and N/C ratios were created. Here we present the calibration procedure done for unshielded material. Since the $\mathrm{C} / \mathrm{O}$ and $\mathrm{N} / \mathrm{C}$ values depend on shielding material too, the same procedure should be repeated for different types of shielding (mineral, metal or organic matrix) which requires some a priori knowledge of the surrounding matrix. 
$\mathrm{T} 1: 1$

$\mathrm{T} 1: 2$

TABLE I

Components and Chemical Formulae of Threat Materials and Their Simulants

\begin{tabular}{|c|c|c|c|c|}
\hline Threat materials & Description & $\begin{array}{l}\text { Chemical } \\
\text { formulae }\end{array}$ & $\begin{array}{l}\text { Chemical formulae } \\
\text { of simulant }\end{array}$ & $\begin{array}{l}\text { Simulant mass } \\
\text { composition }\end{array}$ \\
\hline Hexogen (RDX) & Explosive & $\mathrm{C}_{3} \mathrm{H}_{6} \mathrm{~N}_{6} \mathrm{O}_{6}$ & $\mathrm{Si}_{3} \mathrm{C}_{3} \mathrm{H}_{6} \mathrm{~N}_{6} \mathrm{O}_{6}$ & Melamine 0.412 , Quartz sand 0.588 \\
\hline TNT & Explosive & $\mathrm{C}_{7} \mathrm{H}_{5} \mathrm{~N}_{3} \mathrm{O}_{6}$ & $\mathrm{C}_{7} \mathrm{H}_{6} \mathrm{~N}_{3} \mathrm{O}_{6}$ & $\begin{array}{l}\text { Graphite } 0.158 \text {, Oxalic acid deh. } 0.276 \text {, } \\
\text { Cyanuric acid } 0.566\end{array}$ \\
\hline TATP & Explosive & $\mathrm{C}_{9} \mathrm{H}_{18} \mathrm{O}_{6}$ & $\mathrm{C}_{9} \mathrm{H}_{16.9} \mathrm{O}_{6}$ & Sucrose 0.844 , Paraffin 0.156 \\
\hline DLM2 [7] & Mine simulant & $\mathrm{C}_{7} \mathrm{H}_{5} \mathrm{~N}_{3} \mathrm{O}_{5.5}$ & - & - \\
\hline Cocaine & Drug & $\mathrm{C}_{17} \mathrm{H}_{21} \mathrm{NO}_{4}$ & $\mathrm{C}_{17} \mathrm{H}_{21} \mathrm{NO}_{4}$ & $\begin{array}{l}\text { Melamine } 0.069 \text {, Graphite } 0.243 \text {, } \\
\text { Sucrose } 0.41 \text {, Paraffin } 0.277\end{array}$ \\
\hline Heroin & Drug & $\mathrm{C}_{21} \mathrm{H}_{23} \mathrm{NO}_{5}$ & $\mathrm{C}_{21} \mathrm{H}_{23} \mathrm{NO}_{5}$ & $\begin{array}{l}\text { Melamine } 0.057 \text {, Graphite } 0.294 \text {, } \\
\text { Sucrose } 0.421 \text {, Paraffin } 0.227\end{array}$ \\
\hline Yperite & Chemical warfare & $\mathrm{C}_{4} \mathrm{H}_{8} \mathrm{Cl}_{2} \mathrm{~S}$ & $\mathrm{C}_{4} \mathrm{H}_{8.2-8.4} \mathrm{Cl}_{2} \mathrm{SNa}_{2}$ & $\begin{array}{l}\text { Paraffin } 0.274 \text {, Sodium-chloride } 0.57 \text {, } \\
\text { Sulfur } 0.156\end{array}$ \\
\hline Tetranitromethane & Liquid explosive & $\mathrm{C}\left(\mathrm{NO}_{2}\right)_{4}$ & $\mathrm{Fe}_{4 / 9} \mathrm{C}_{4 / 3}\left(\mathrm{NO}_{2}\right)_{4} \mathrm{H}_{32 / 3}$ & $\begin{array}{l}\text { Iron(III) nitrate nonahydrate } 0.762 \text {, } \\
\text { Melamine } 0.238\end{array}$ \\
\hline Peroxide methylethylketone & Liquid explosive & $\mathrm{C}_{8} \mathrm{H}_{18} \mathrm{O}_{6}$ & $\mathrm{C}_{8} \mathrm{H}_{12} \mathrm{O}_{6}$ & Sucrose 0.914 , Graphite 0.086 \\
\hline Nitromethane & Liquid explosive & $\mathrm{CH}_{3} \mathrm{NO}_{2}$ & $\mathrm{Fe}_{1 / 3} \mathrm{CH}_{5 / 2} \mathrm{NO}_{2}$ & $\begin{array}{l}\text { Oxalic acid dehydrated } 0.398 \text {, Melamine } \\
0.266 \text {, Iron(III) oxide } 0.336\end{array}$ \\
\hline Ethyleneglycol dinitrate & Liquid explosive & $\left(\mathrm{CH}_{2} \mathrm{ONO}_{2}\right)_{2}$ & $\mathrm{FeCH}_{5 / 2} \mathrm{NO}_{3}$ & $\begin{array}{l}\text { Oxalic acid dehydrated } 0.238 \text {, Melamine } \\
0.159 \text {, Iron(III) oxide } 0.603\end{array}$ \\
\hline
\end{tabular}

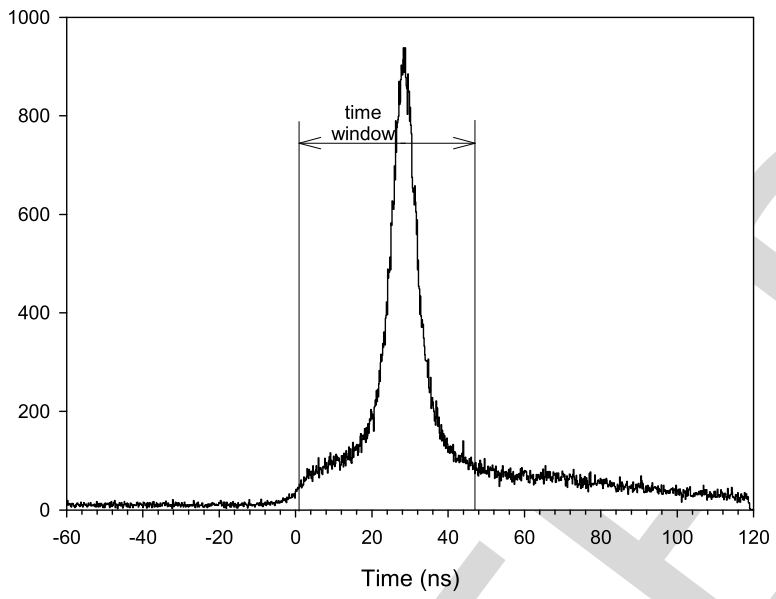

F2:1 $\mathrm{F} 2: 2$

Fig. 2. Typical time-of-flight spectrum (output from TAC) with indicated time window used in data analysis.

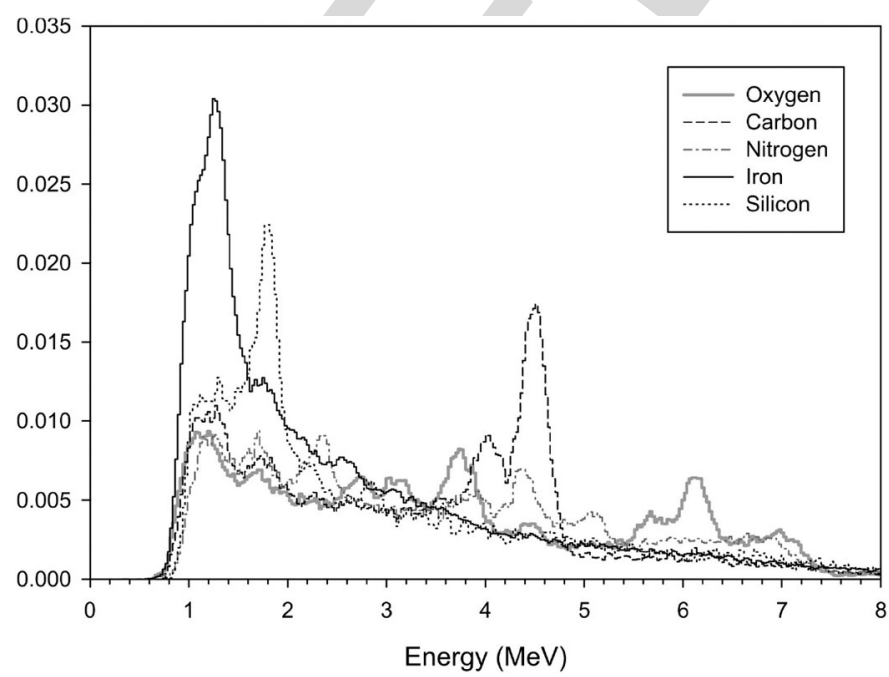

F3:1 Fig. 3. Gamma spectra of elements used for fitting procedure.
TABLE II

Mass COMPosition of Standards PREPARED For C/O CALIBration T2:2

$\mathrm{C} / \mathrm{O} \quad$ Composition

1/3 Graphite 0.118 , quartz sand 0.882

1/2 Graphite 0.167 , quartz sand 0.833

$1 \quad$ Graphite 0.286 , quartz sand 0.714

$2 \quad$ Graphite 0.444 , quartz sand 0.556

$4 \quad$ Graphite 0.615 , quartz sand 0.385

TABLE III

MASS COMPosition of Standards Prepared For N/C CALIBRATION T3:2

\begin{tabular}{ll}
$\mathrm{N} / \mathrm{C}$ & Composition \\
\hline $1 / 21$ & Iron(III) nitrate nonahydrate 0.348, graphite 0.652 \\
$3 / 7$ & Iron(III) nitrate nonahydrate 0.828, graphite 0.172 \\
2.5 & Iron(III) nitrate nonahydrate 0.616, melamine 0.384 \\
3.5 & Iron(III) nitrate nonahydrate 0.828, melamine 0.172
\end{tabular}

\section{METHODS}

Fig. 1 shows the experimental setup. A neutron generator (NG) ThermoElectron API 120 was used as a source of $14 \mathrm{MeV}$ (fast) neutrons (cca $10^{7} \mathrm{n} / \mathrm{s}$ in $4 \pi$ ) produced by ${ }^{3} \mathrm{H}(\mathrm{d}, \mathrm{n}){ }^{4} \mathrm{He}$ nuclear reaction. Since ${ }^{4} \mathrm{He}$ (alpha) particle is produced in opposite direction from the neutron, it is possible to tag and electronically collimate neutrons by detecting coincides between alpha particles and gamma rays emitted from the nuclei in the measured object excited by the inelastic scattering with tagged neutrons [6]. The alpha detector incorporated inside the NG was made from the YAP:Ce scintillator fixed to the NG, and removable photomultiplier tube (PMT). The collimator in front of the PMT defined the tagged neutron cone opening angle of $12^{\circ}$. The $7.62 \mathrm{~cm} \times 7.62 \mathrm{~cm}$ Bismuth Germanium Oxide, $\mathrm{Bi}_{4} \mathrm{Ge}_{3} \mathrm{O}_{12}$ detector (BGO) was used for the detection of characteristic gamma rays. The BGO energy resolution was $7 \%$ at $4.44 \mathrm{MeV}$ carbon peak. A pyramid made of iron, $40 \mathrm{~cm}$ in length, was used as a shield for detector protection from direct neutron radiation. A measured sample was put below the gamma ray detector $5 \mathrm{~cm}$ apart from the detector. The distance between the neutron source and the gamma 
T4:1

T4:2

T5:1

T5:2

T6:1

T6:2

T7:1

T7:2

T8:1

T8:2

TABLE IV

UNFOLDING RESULTS FOR C/O CALIBRATION STANDARDS

\begin{tabular}{lllllll}
$\mathrm{C} / \mathrm{O}$ & Oxygen (a) & Carbon $(\mathrm{b})$ & Nitrogen $(\mathrm{c})$ & Iron $(\mathrm{d})$ & Silicon $(\mathrm{e})$ & $\mathrm{b} / \mathrm{a}$ \\
\hline $1 / 3$ & $0.45 \pm 0.007$ & $0.135 \pm 0.005$ & $-0.03 \pm 0.01$ & $-0.10 \pm 0.01$ & $0.54 \pm 0.01$ & $0.30 \pm 0.01$ \\
$1 / 2$ & $0.395 \pm 0.008$ & $0.160 \pm 0.005$ & $-0.01 \pm 0.01$ & $-0.015 \pm 0.012$ & $0.47 \pm 0.01$ & $0.405 \pm 0.015$ \\
1 & $0.326 \pm 0.009$ & $0.277 \pm 0.006$ & $-0.008 \pm 0.01$ & $0.032 \pm 0.014$ & $0.37 \pm 0.01$ & $0.85 \pm 0.03$ \\
2 & $0.259 \pm 0.008$ & $0.401 \pm 0.006$ & $0.03 \pm 0.01$ & $-0.01 \pm 0.01$ & $0.31 \pm 0.01$ & $1.55 \pm 0.05$ \\
4 & $0.181 \pm 0.009$ & $0.588 \pm 0.007$ & $0.005 \pm 0.01$ & $0.02 \pm 0.01$ & $0.20 \pm 0.01$ & $3.25 \pm 0.2$ \\
\hline
\end{tabular}

TABLE V

Actual Relative Mass Concentration of Oxygen, Carbon, Nitrogen, Iron and Silicon for C/O Calibration Standards

\begin{tabular}{lcccccc}
$\mathrm{C} / \mathrm{O}$ & Oxygen & Carbon & Nitrogen & Iron & Silicon & Carbon/Oxygen \\
\hline $1 / 3$ & 0.47 & 0.12 & 0 & 0 & 0.41 & 0.25 \\
$1 / 2$ & 0.44 & 0.17 & 0 & 0 & 0.39 & 0.39 \\
1 & 0.38 & 0.29 & 0 & 0 & 0.33 & 0.76 \\
2 & 0.30 & 0.44 & 0 & 0 & 0.18 & 1.47 \\
4 & 0.21 & 0.61 & 0 & 0 & 0.90 & 2.90 \\
\hline
\end{tabular}

TABLE VI

UNFOLDING RESULTS FOR N/C CALIBRATION STANDARDS

\begin{tabular}{lclllll}
$\mathrm{N} / \mathrm{C}$ & Oxygen $(\mathrm{a})$ & Carbon $(\mathrm{b})$ & Nitrogen $(\mathrm{c})$ & Iron $(\mathrm{d})$ & Silicon $(\mathrm{e})$ & $\mathrm{c} / \mathrm{b}$ \\
\hline $1 / 21$ & $0.245 \pm 0.009$ & $0.622 \pm 0.008$ & $0.06 \pm 0.01$ & $0.12 \pm 0.01$ & $-0.055 \pm 0.01$ & $0.096 \pm 0.023$ \\
$3 / 7$ & $0.676 \pm 0.009$ & $0.172 \pm 0.006$ & $0.10 \pm 0.01$ & $0.075 \pm 0.01$ & $0.0131 \pm 0.0095$ & $0.59 \pm 0.08$ \\
2.5 & $0.480 \pm 0.010$ & $0.133 \pm 0.006$ & $0.285 \pm 0.015$ & $0.11 \pm 0.01$ & $0.025 \pm 0.01$ & $2.14 \pm 0.15$ \\
3.5 & $0.585 \pm 0.010$ & $0.068 \pm 0.007$ & $0.19 \pm 0.02$ & $0.15 \pm 0.02$ & $0.02 \pm 0.01$ & $3.0 \pm 0.5$ \\
\hline
\end{tabular}

TABLE VII

Actual Relative Mass Concentration of Oxygen, Carbon, Nitrogen, Iron and Silicon for N/C Calibration Standards

\begin{tabular}{lclclcc} 
N/C & Oxygen & Carbon & Nitrogen & Iron & Silicon & Nitrogen/Carbon \\
\hline $1 / 21$ & 0.248 & 0.652 & 0.036 & 0.048 & 0 & 0.055 \\
$3 / 7$ & 0.590 & 0.172 & 0.086 & 0.114 & 0 & 0.5 \\
2.5 & 0.439 & 0.11 & 0.320 & 0.085 & 0 & 2.9 \\
3.5 & 0.590 & 0.049 & 0.201 & 0.114 & 0 & 4.1 \\
\hline
\end{tabular}

TABLE VIII

UNFOLding REsults For MEASUREd Simulants OF THREAT Materials

\begin{tabular}{llllll} 
Item (simulants) & Oxygen (a) & Carbon (b) & Nitrogen (c) & Iron (d) & Silicon (e) \\
\hline Hexogen (RDX) & $0.297 \pm 0.009$ & $0.126 \pm 0.006$ & $0.220 \pm 0.01$ & $0.011 \pm 0.014$ & $0.35 \pm 0.01$ \\
TNT & $0.45 \pm 0.01$ & $0.369 \pm 0.007$ & $0.20 \pm 0.01$ & $0.007 \pm 0.01$ & $-0.002 \pm 0.01$ \\
TATP & $0.45 \pm 0.01$ & $0.535 \pm 0.008$ & $0.02 \pm 0.01$ & $0.02 \pm 0.01$ & $-0.04 \pm 0.01$ \\
DLM2 & $0.34 \pm 0.01$ & $0.35 \pm 0.008$ & $0.15 \pm 0.02$ & $0.165 \pm 0.017$ & $0.01 \pm 0.01$ \\
Cocaine & $0.205 \pm 0.009$ & $0.748 \pm 0.008$ & $0.082 \pm 0.014$ & $0.038 \pm 0.015$ & $-0.05 \pm 0.01$ \\
Heroin & $0.24 \pm 0.009$ & $0.762 \pm 0.008$ & $0.03 \pm 0.014$ & $0.033 \pm 0.014$ & $-0.04 \pm 0.01$ \\
Yperite & - & - & - & - & - \\
Tetranitromethane & $0.53 \pm 0.01$ & $0.087 \pm 0.007$ & $0.222 \pm 0.015$ & $0.163 \pm 0.015$ & $0.015 \pm 0.012$ \\
Peroxide methylethylketone & $0.488 \pm 0.009$ & $0.525 \pm 0.007$ & $0.007 \pm 0.013$ & $0.017 \pm 0.013$ & $-0.02 \pm 0.01$ \\
Nitromethane & $0.447 \pm 0.009$ & $0.16 \pm 0.006$ & $0.19 \pm 0.01$ & $0.21 \pm 0.01$ & $0.01 \pm 0.01$ \\
Ethyleneglycol dinitrate & $0.408 \pm 0.009$ & $0.111 \pm 0.006$ & $0.12 \pm 0.01$ & $0.37 \pm 0.01$ & $0.015 \pm 0.01$ \\
\hline
\end{tabular}

ray detector was $50 \mathrm{~cm}$. All samples had mass of $1 \mathrm{~kg}$, except DLM2 anti-personal mine simulant [7] which mass was $192.6 \mathrm{~g}$ and volume $\Phi 80 \mathrm{~mm} \times 34.5 \mathrm{~mm}$.

Measured samples, chemical formulae of the real materials and measured simulants (when applicable), as well as compounds used to make simulants are presented in Table I.

Each measurement lasted $1000 \mathrm{~s}$ and was normalized to the same number of emitted tagged neutrons. The fast output from the alpha detector was fed through the constant fraction discriminator (CFD) and delay line to the STOP of the timeto-amplitude converter (TAC). The fast output from the gamma ray detector was fed through the timing filter amplifier and CFD to the START of the TAC. A slow signal from the gamma ray 110 detector was fed through the amplifier to the analog-to-digital 111 converter (ADC) incorporated inside the personal computer 112 together with the output from TAC (time spectrum). The ADC 113 was triggered by a single channel analyzer (SCA) output from 114 TAC. Fig. 2 shows the typical time spectrum. A wider time win- 115 dow was used for the gamma ray spectra analysis in order to 116 obtain more statistics (counts) and accordingly smaller error 117 bars in the gamma ray peaks. This improved the detection 118 probabilities.

Gamma ray spectra were fitted according to the equation (1) 120 which is simple unfolding model developed for this purpose. 121 
T9:1

TABLE IX

actual Relative Mass Concentration of Oxygen, Carbon, Nitrogen, Iron and Silicon for Simulants of Threat Materials

\begin{tabular}{llllll} 
Item (simulants) & Oxygen & Carbon & Nitrogen & Iron & Silicon \\
\hline Hexogen (RDX) & 0.313 & 0.118 & 0.274 & 0 & 0.275 \\
TNT & 0.421 & 0.368 & 0.184 & 0 & 0 \\
TATP & 0.434 & 0.489 & 0 & 0 & 0 \\
DLM2 & 0.401 & 0.384 & 0.192 & 0 & 0 \\
Cocaine & 0.211 & 0.673 & 0.046 & 0 & 0 \\
Heroin & 0.216 & 0.683 & 0.038 & 0 & 0 \\
Yperite & - & - & - & - & - \\
Tetranitromethane & 0.543 & 0.068 & 0.238 & 0.105 & 0 \\
Peroxide methylethylketone & 0.470 & 0.471 & 0 & 0 & 0 \\
Nitromethane & 0.404 & 0.152 & 0.177 & 0.235 & 0 \\
Ethyleneglycol dinitrate & 0.362 & 0.091 & 0.106 & 0.422 & 0 \\
\hline
\end{tabular}

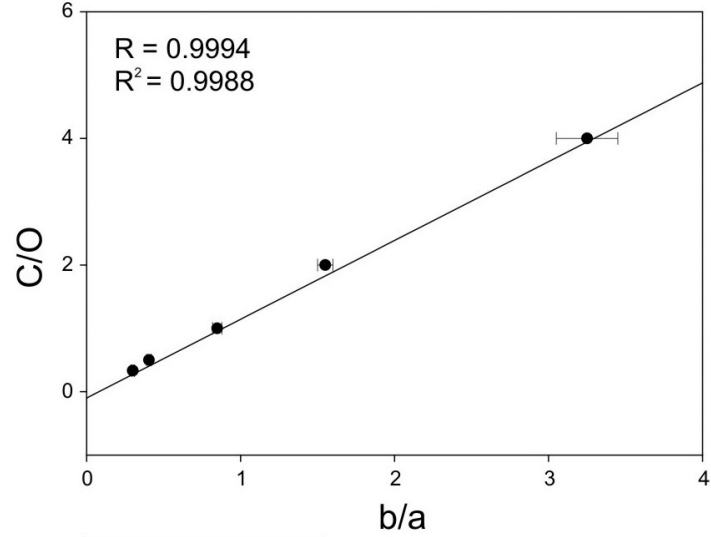

- fitting curve experimental data

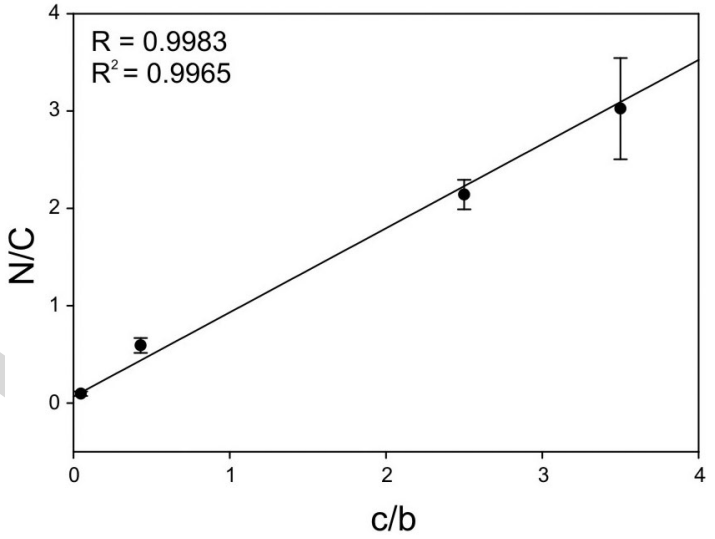

experimental data
F4:1 Fig. 4. The stoichiometric $\mathrm{C} / \mathrm{O}$ values in dependence on the fitting parameters $\mathrm{F} 4: 2$ ratio for $\mathrm{C} / \mathrm{O}$ calibration standards. Standard error of estimate: $6 \%$.
Fig. 5. The stoichiometric N/C values in dependence on the fitting parameters F5:1 ratio for N/C calibration standards. Standard error of estimate: $12 \%$.

$$
\begin{aligned}
& \chi^{2}=\frac{\text { summ }^{2}}{c h_{\max }-c h_{\min }-5+1} \\
& \times \sum_{c h=c h_{\min }}^{c h_{\max }} \frac{\left(a \times O(c h)+b \times C(c h)+c \times N(c h)+d \times F e(c h)+e \times S i(c h)-\frac{T \arg \text { et }(\text { ch })}{\text { summ }}\right)^{2}}{T \arg e t(c h)} \\
& \sum_{c h=c h_{\min }}^{c h_{\max }} T \arg e t(c h)=s u m m \\
& \sum_{c h=c h_{\min }}^{c h_{\max }} O(c h)=1 \\
& \sum_{c h=c h_{\min }}^{c h_{\max }} C(c h)=1 \\
& \sum_{c h=c h_{\min }}^{c h_{\max }} N(c h)=1 \\
& \sum_{c h=c h_{\min }}^{c h_{\max }} F e(c h)=1 \\
& \sum_{c h=c h_{\min }}^{c h_{\max }} S i(c h)=1
\end{aligned}
$$



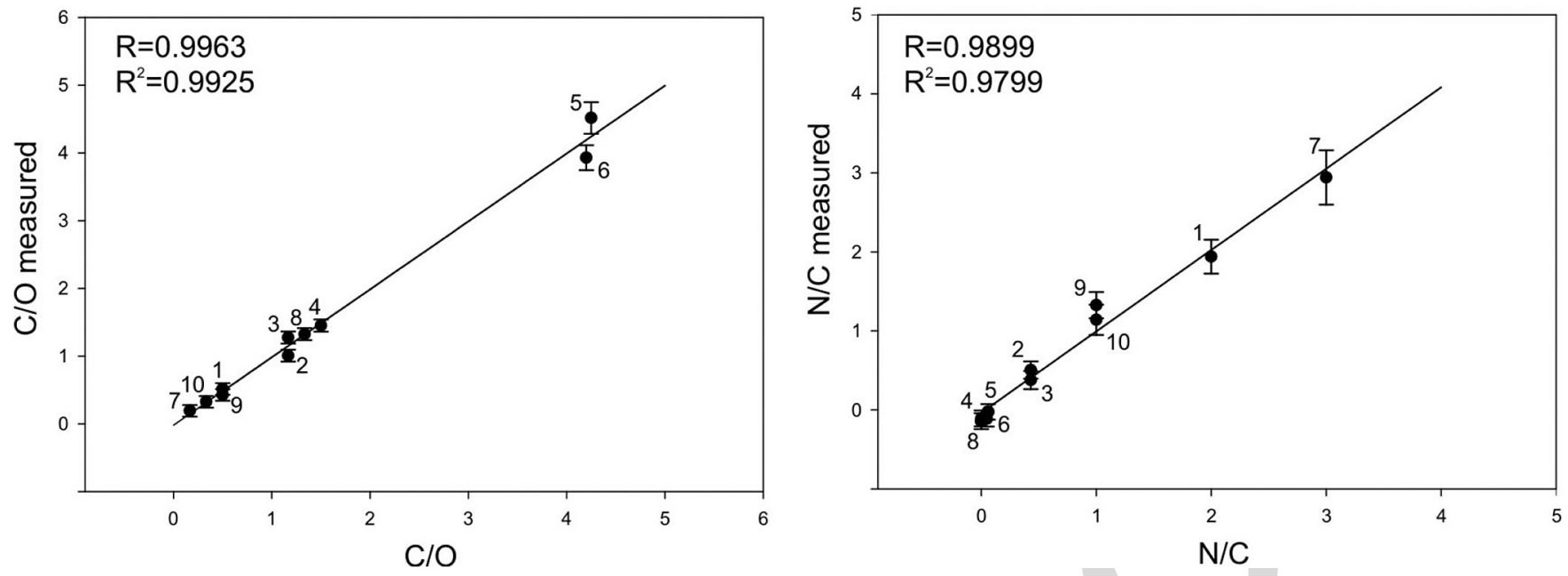

F6:1 Fig. 6. Correlations b $\mathrm{b}$ stoichiometric and experimentally obtained values for $\mathrm{C} / \mathrm{O}$ ratio (left) and N/C ratio (right) for different types of threat materials as

TABLE X

Comparison Between Measured and Stoichiometric C/O Values OF THREAT MATERIAL SimUlantS

\begin{tabular}{|c|c|c|c|c|}
\hline ID & Simulant & $\begin{array}{l}\mathrm{C} / \mathrm{O} \text { from } \\
\text { stoichiometry }\end{array}$ & $\begin{array}{l}\mathrm{C} / \mathrm{O} \text { from } \\
\text { measurement }\end{array}$ & Difference \\
\hline 1. & Hexogen & 0.500 & $0.514 \pm 0.085$ & $-0.16 \sigma$ \\
\hline 2. & TNT & 1.17 & $1.01 \pm 0.09$ & $1.8 \sigma$ \\
\hline 3. & DLM2 & 1.17 & $1.27 \pm 0.09$ & $-1.1 \sigma$ \\
\hline 4. & TATP & 1.50 & $1.45 \pm 0.09$ & $0.55 \sigma$ \\
\hline 5. & Cocaine & 4.25 & $4.52 \pm 0.23$ & $-1.2 \sigma$ \\
\hline 6. & Heroin & 4.2 & $3.9 \pm 0.2$ & $1.5 \sigma$ \\
\hline 7. & $\begin{array}{l}\text { Tetranitro- } \\
\text { methane }\end{array}$ & 0.167 & $0.192 \pm 0.085$ & $0.3 \sigma$ \\
\hline 8. & $\begin{array}{l}\text { Peroxide } \\
\text { methyl- } \\
\text { ethylketone }\end{array}$ & 1.33 & $1.32 \pm 0.09$ & $0.11 \sigma$ \\
\hline 9. & Nitromethane & 0.500 & $0.428 \pm 0.085$ & $0.85 \sigma$ \\
\hline 10. & $\begin{array}{c}\text { Ethylenglycol } \\
\text { dinitrate }\end{array}$ & 0.333 & $0.324 \pm 0.085$ & $0.1 \sigma$ \\
\hline ID & Simulant & $\begin{array}{l}\text { N/C from } \\
\text { stoichiometry }\end{array}$ & $\begin{array}{l}\mathrm{N} / \mathrm{C} \text { from } \\
\text { measurement }\end{array}$ & Difference \\
\hline 1. & Hexogen & 2 & $1.9 \pm 0.2$ & $0.5 \sigma$ \\
\hline 2. & TNT & 0.43 & $0.5 \pm 0.1$ & $-0.7 \sigma$ \\
\hline 3. & DLM2 & 0.43 & $0.4 \pm 0.1$ & $0.3 \sigma$ \\
\hline 4. & TATP & 0 & $-0.1 \pm 0.1$ & $1 \sigma$ \\
\hline 5. & Cocaine & 0.059 & $-0.026 \pm 0.098$ & $0.9 \sigma$ \\
\hline 6. & Heroin & 0.0476 & $-0.112 \pm 0.098$ & $1.6 \sigma$ \\
\hline 7. & $\begin{array}{l}\text { Tetranitro- } \\
\text { methane }\end{array}$ & 3 & $2.9 \pm 0.3$ & $0.3 \sigma$ \\
\hline 8. & $\begin{array}{l}\text { Peroxide } \\
\text { methyl- } \\
\text { ethylketone }\end{array}$ & 0 & $-0.1 \pm 0.1$ & $1 \sigma$ \\
\hline 9. & Nitromethane & 1 & $1.3 \pm 0.2$ & $1.5 \sigma$ \\
\hline 10. & $\begin{array}{c}\text { Ethylenglycol } \\
\text { dinitrate }\end{array}$ & 1 & $1.1 \pm 0.2$ & $0.5 \sigma$ \\
\hline
\end{tabular}

The model assumes that gamma ray spectra contain only the following chemical elements: oxygen, carbon, nitrogen, iron and silicon. The fitting parameters from eq. (1) are marked with "a" for oxygen, "b" for carbon, "c" for nitrogen, "d" for iron and "e" for silicon and the values are summed from minimum to maximum channel and normalized to 1 . The method of least squares states that the best value of "a", "b", "c", "d" and "e"
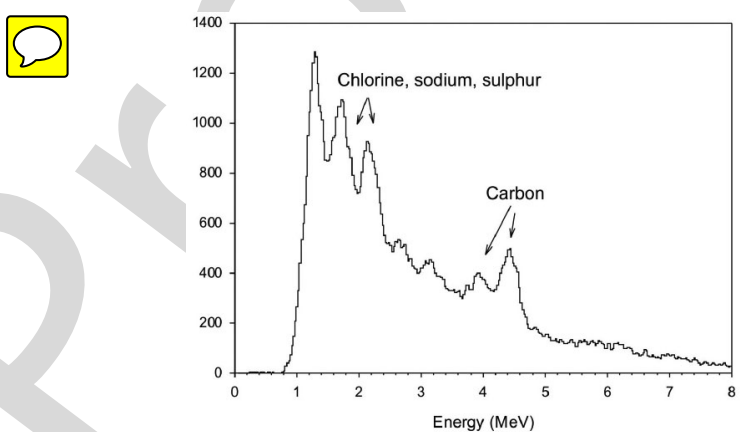

Fig. 7. Gamma spectrum obtained for yperite simulant.

are the one for which the reduced chi-square (defined in eq.1 130 and [8]) is minimal. In practice, values of reduced chi-square 131 close to 1 are acceptable for obtaining a good spectrum fitting. 132 [See equation (1), shown at the bottom of the previous page.] 133

A number of counts in the gamma ray spectra of carbon are 134 marked with C (ch) and similarly for other elements. A num- 135 ber of counts in the sample spectrum are marked with Target 136 (ch). Spectra obtained for elements oxygen, carbon, nitrogen, 137 iron and silicon are presented in Fig. 3. Oxygen spectrum was 138 obtained by analysis of water, carbon spectrum by analysis of 139 graphite, iron spectrum by analysis of the iron metal plate, 140 nitrogen spectrum by analysis of melamine from which the 141 carbon contribution was subtracted and silicon spectrum was 142 obtained by analysis of quartz sand. In order to quantitatively 143 determine $\mathrm{C} / \mathrm{O}$ and $\mathrm{N} / \mathrm{C}$ ratios, standard materials of known 144 $\mathrm{C} / \mathrm{O}$ and N/C ratios were prepared for calibration purposes 145 as shown in Tables II and III. The C/O and N/C ratios were 146 selected because the differences in their values distinguish the 147 wide spectrum of threat materials.

\section{RESUlTS AND DISCUSSION}

Aim of the developed calibration procedure was to relate the 150 measured $\mathrm{b} / \mathrm{a}$ and $\mathrm{c} / \mathrm{b}$ ratios with the stoichiometric values of the 151 calibration standards which compositions are shown in Table II 152 

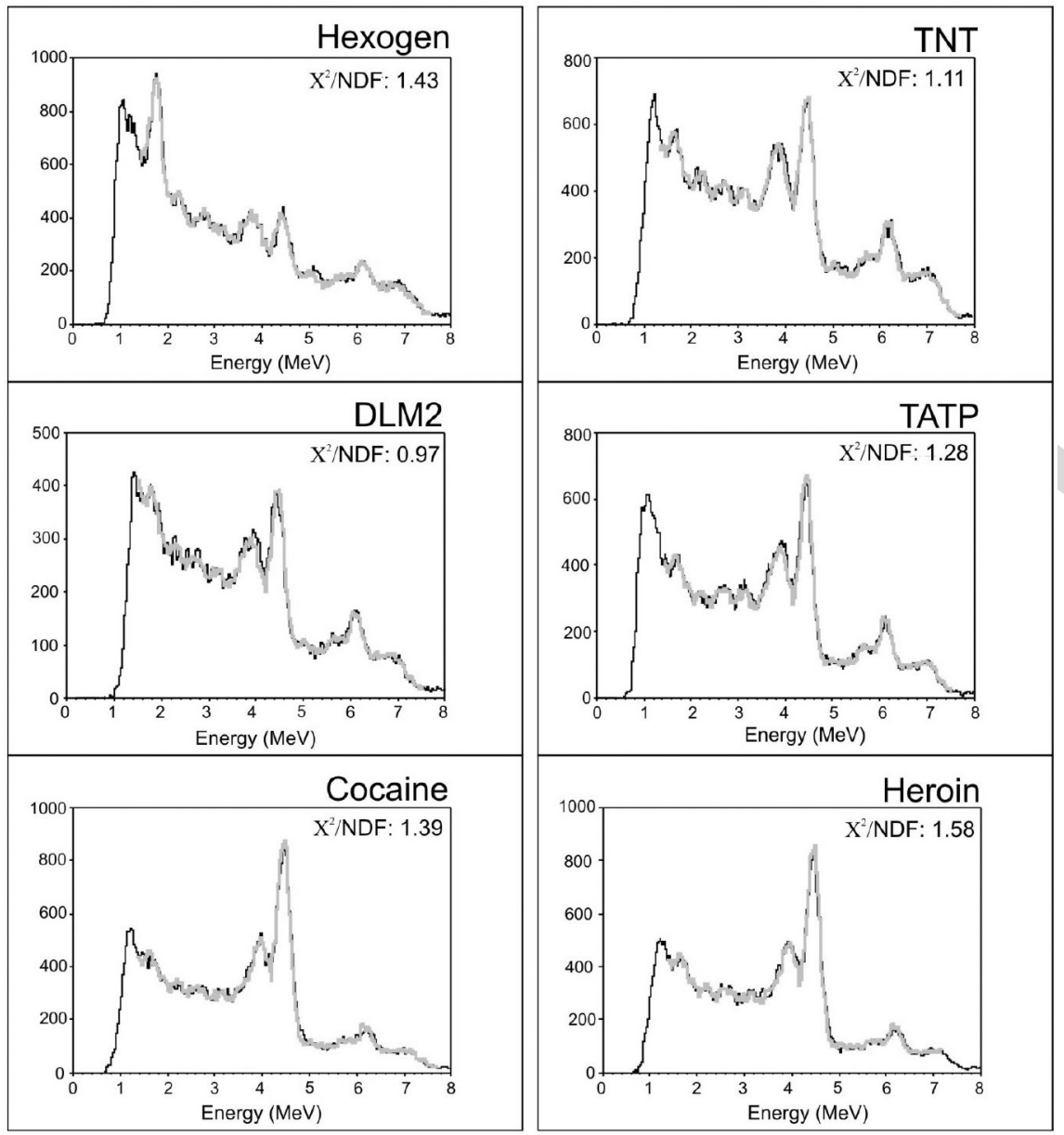

F8:1 Fig. 8. Gamma spectra for simulants of bulk explosives, cocaine and heroin. Fitted spectra are in grey.
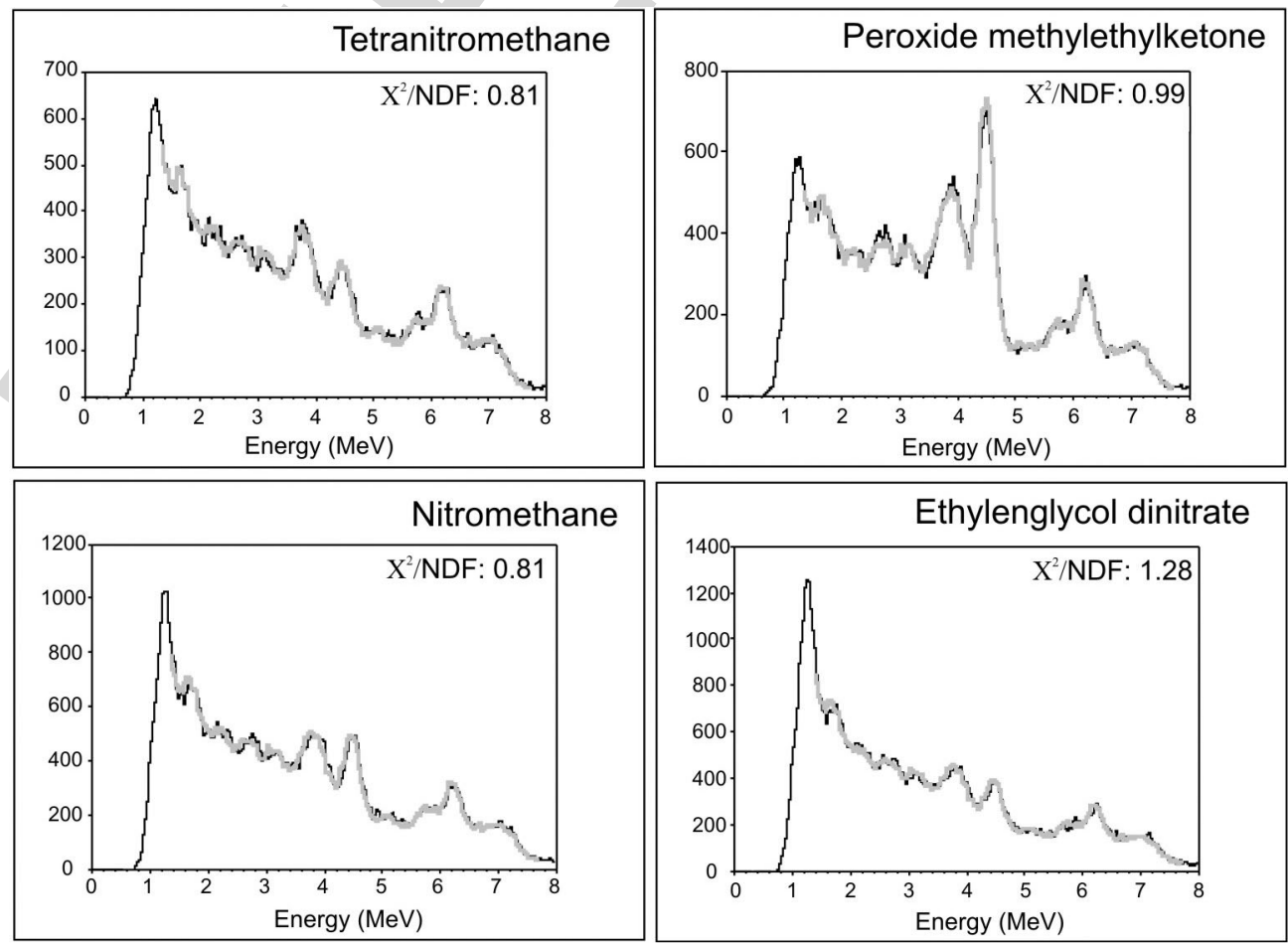

F9:1 Fig. 9. Gamma spectra for simulants of liquid explosives. Fitted spectra are in grey. 
and III. The method of least squares was used to obtain "a", "b", "c", "d" and "e" fitting parameters with minimum chi-square value which results are presented in Table IV and VI. Negative values of fitting parameters have to be interpreted as zero values within the standard errors of estimate. Actual relative mass concentration of oxygen, carbon, nitrogen, iron and silicon for $\mathrm{C} / \mathrm{O}$ and $\mathrm{N} / \mathrm{C}$ calibration standards are given in table $\mathrm{V}$ and VII, respectively. Figs. 4 and 5 show the stoichiometric $\mathrm{C} / \mathrm{O}$ and $\mathrm{N} / \mathrm{C}$ values in dependence on the fitting parameter ratios b/a and $\mathrm{c} / \mathrm{b}$, respectively. Lines were fitted through the experimentally obtained points with the fitting parameters shown in eq. (2) and (3). These calibration lines were used to obtain experimental $\mathrm{C} / \mathrm{O}$ and N/C values for measured simulants. Fitting parameters obtained for "a", "b", "c", "d" and "e" in simulants are presented in Table VIII and actual relative mass concentrations of $\mathrm{O}, \mathrm{Si}, \mathrm{N}, \mathrm{Fe}$ and $\mathrm{Si}$ in simulants in Table IX.

Linear correlations between theoretical and experimental ratios of $\mathrm{C} / \mathrm{O}$ and N/C for hexogen (RDX), TNT, DLM2, TATP, cocaine, heroin, tetranitromethane, peroxide methylethylketone, nitromethane and ethylenglycol dinitrate are shown in eq. (4) and (5) and Fig. 6. Expected slope and segment of the correlation function are 1 and 0 , respectively. The total error comprises errors obtained for segment and slope. Since both $\mathrm{C} / \mathrm{O}$ and N/C ratios have slopes and segments close to 1 and 0 respectively (within the error bar), it can be concluded that the calibration procedure is consistent. Tables $\mathrm{X}$ and $D$ how the comparison between measured and stoichiometric $\mathrm{C} / \mathrm{O}$ and $\mathrm{N} / \mathrm{C}$ values respectively, as well as the individual errors resulting from the spectrum fitting. The error bars depend on many factors, however they diminish with the extension of the measurement time. This calibration procedure enables experimental determination of $\mathrm{C} / \mathrm{O}$ and $\mathrm{N} / \mathrm{C}$ values by analyzing the adequate standards (Tables II and III) and testing the quality of calibration by analyzing simulants prepared as reference materials (Table I). This approach is different compared to the methodology described in [5] where Monte Carlo simulation was used to determine $\mathrm{C} / \mathrm{O}$ and $\mathrm{N} / \mathrm{C}$ values. Applied calibration procedure should be repeated for a shielded material, e.g. for inspected material shielded within metal, mineral or organic matrix having realistic densities obtained from a real cargo [9]. By using this procedure it is possible to obtain correction factors for different types of cargo.

$\mathrm{C} / \mathrm{O}($ experimental $)=(-0.1 \pm 0.04)+(1.244 \pm 0.025) \mathrm{b} / \mathrm{a}$

$\mathrm{N} / \mathrm{C}($ experimental $)=(-0.16 \pm 0.095)+(1.215 \pm 0.051) \mathrm{c} / \mathrm{b}$

$\mathrm{C} / \mathrm{O}=(-0.02 \pm 0.07)+(1.0 \pm 0.03) \mathrm{C} / \mathrm{O}($ experimental $)$

$\mathrm{N} / \mathrm{C}=(-0.04 \pm 0.07)+(1.03 \pm 0.05) \mathrm{N} / \mathrm{C}($ experimental $)$
Fig. 7 presents gamma spectrum obtained for yperite. This 195 spectrum was not fitted since it does not contain $\mathrm{N}$ and O peaks. 196 Fig. 8 presents fitted gamma spectra of measured bulk explo- 197 sives and drugs and Fig. 9 shows fitted spectra of measured 198 liquid explosives. Note that the reduced chi-squares of fitted 199 spectra showed in Fig. 8 and 9 were all close to one, hence the 200 fitting results are acceptable.

\section{CONCLUSION}

We have proposed new experimental approach for the neu- 203 tron interrogation system calibration. Calibration standards and 204 simulants of threat materials were created. Materials and quan- 205 tities necessary for their production have been listed, thus 206 developers of neutron interrogation systems can produce their 207 own calibration standards and threat material simulants as ref- 208 erence materials. A simple unfolding model for determination 209 of $\mathrm{C} / \mathrm{O}$ and $\mathrm{N} / \mathrm{C}$ ratios has been developed. It has been shown 210 that analyses of the gamma ray spectra by using this unfolding 211 model gave a nice agreement with the C/O and N/C stoichio- 212 metric ratios of simulants, hence the calibration quality was 213 successfully tested. In future work influence of the surround- 214 ing matrix to $\mathrm{C} / \mathrm{O}$ and $\mathrm{N} / \mathrm{C}$ ratios in simulants of threat material 215 will be studied.

\section{ACKNOWLEDGMENT}

The authors would like to express their gratitude to unknown 218 reviewers whose careful reading and comments significantly 219 improved the paper.

\section{REFERENCES}

[1] Secure Freight Initiative, Section 232 of the Safe Ports Act of 2006. 222

[2] V. Valkovic et al., "Inspection of shipping containers for threat materials," 223 Radiat. Phys. Chem., vol. 71, pp. 897-898, 2004.

[3] C. Carasco et al., "In-field tests of the EURITRACK tagged neutron 225 inspection system," Nucl. Instrum. Methods Phys. Res. A, vol. 588, 226 pp. 397-405, 2008 .

[4] Examples: http://neutrontech.jinr.ru/index.php?id=products, http://www. 228 sodern.com/sites/en/ref/Homeland-Security-and-Defense_34.html 229

[5] W. El Kanawati et al., "Conversion factors from counts to chemical ratios 230 for the EURITRACK tagged neutron inspection system," Nucl. Instrum. 231 Methods Phys. Res. A, vol. 654, pp. 621-629, 2011.

[6] D. Sudac, S. Blagus, V. Valkovic, "Inspections for contraband in a 233 shipping container using fast neutrons and the associated alpha parti- 234 cle technique: Proof of principle," Nucl. Instrum. Methods Phys. Res. B, 235 vol. 241, pp. 798-803, 2005.

[7] F. D. Brooks, M. Drosg, A. Buffler, and M. S. Allie, "Detection of antipersonnel landmines by neutron scattering and attenuation," Appl. Radiat. 238 Isot., vol. 61, pp. 27-34, 2004.

[8] W. R. Leo, Techniques for Nuclear and Particle Physics Experiments, 240 Berlin, Germany: Springer-Verlag, 1987, pp. 99.

[9] J. Obhodas et al., "Analysis of containerized cargo in the ship container 242 terminal," Nucl. Instrum. Methods Phys. Res. A, vol. 619, pp. 460-466, 243 2010 . 


\section{QUERY}

Q1: Please supply index terms/keywords for your paper. To download the IEEE Taxonomy, go to http://www.iee.org/documents/ taxonomy_v101.pdf. 